\title{
VI.
}

Arbeiten aus dem pharmakologischen Laboratorium zu Mtinchen.

\section{Beiträge zur Kenntniss der Wirkungen des Solanins und Solanidins. ${ }^{1}$ )}

\author{
Von \\ Max Porles. \\ (Hierzu Taf. III u. IV.)

\section{Solanin.}

Das Solanin wurde im Jahre 1820 von dem Apotheker Des fosses aus Besançon in mehreren Organen von Solanum nigrum und dulcamara L. entdeckt und 1826 von Baup in den Kartoffeln, namentlich in den Trieben derselben nachgewiesen. Seitdem sind gegen 50 Arbeiten chemischen und über 30 pharmakologisch-toxikologisehen Inhalts, soweit ich die Literatur übersehe, über Solanin ersehienen. ${ }^{2}$ )

Die einzige mit modernen Methoden ausgeführte pharmakologische Untersuchung über Solanin und Solanidin ist die von Balmañya und Husemann. ${ }^{3}$ ) Dieselben bedienten sich ausschliesslich der subcutanen Injection und beschreiben das hierbei an Kaninchen, Tauben, Fröschen und Salamandern bewirkte Vergiftungsbild: im ersten Stadium centrale, absteigende Lähmung, Herzlähmung, Temperaturherabsetzung (nur durch Solanin); im zweiten Stadium asphyktische Krämpfe und Mydriasis (letztere durch Solanidin bereits frühzeitig), Tod durch Lähmung des Respirationscentrums. - Die Punkte, in

1) Von der medicinischen Facultät der kgl. Universität zu München 1888 gekrönte Preisschrift. (Im Auszuge mitgetheilt.)

2) Das Verzeichniss derselben mit Inhaltsangabe siehe S. 128-132. Eine kurze Besprechung der wichtigsten pharmakologischen Arbeiten und die vorhandene ziemlich dürftige Vergiftungscasuistik findet sich in meiner demnächst erscheinenden Dissertation. Dortselbst sind auch die wegen Raummangels hier weggelassenen Versuchsbelege, sowie die wichtigsten Angaben niedergelegt über Fundorte, Darstellungsmethoden, Nachweis, Reactionen u. s. w. Speciell mit den Reactionen des Solanins und Solanidins habe ich mich etwas eingehender beschäftigt und u. A. auch die durch concentrirte Mineralsäuren daraus entstehenden gefärbten Producte, soweit möglich, auf ihr spectroskopisches Verhalten untersucht.

3) Göttinger Dissert. 1874. Dieses Archiv 1875. IV. Bd. S. 369. 
welchen meine Beobachtungen von denen Husemann's und Balmañy a's abweichen, sind später erwähnt.

Das zu meinen Versuchen benutzte Solanin war von Trommsdorff in Erfurt bezogen und aus Kartoffeltrieben hergestellt. Ausdrücklich sei erwähnt, dass sich alles Folgende vorläufig, ehe die Identität des Solanins aus verschiedenen Solaneen bewiesen ist, nur auf Kartoffelsolanin bezieht. Das Präparat war völlig farblos und gut krystallisirt; um eventuell anwesendes Solanidin zu entfernen, wurde dasselbe mehrmals, erst mit kaltem Aether im Schïttelcylinder, dann mit siedendem im Extractionsapparat ausgezogen, bis der Aether nichts mehr aufnahm, dann wiederholt aus 90 proc. Alkohol umkrystallisirt. Es waren schöne, bis $1 \mathrm{~cm}$ lange, radiär büschelförmig geordnete Nadeln, unter dem Mikroskop rechtwinkelig-vierseitige Prismen. Auf dem Filter gesammelt und getrocknet war es ein farb- und geruchloses, perlglänzendes lockeres Pulver. Dasselbe entsprach allen bisher wohlbeobachteten Reactionen des Solanins und war nachweisbar Solanidin-fiei, enthielt jedoch 0,45 Proc. Asche, die auf keine Weise eliminirbar war. Herr Dr. $\mathrm{Nakahama}$ aus Japan, dem ich für seine Gefälligkeit sehr verbunden bin, führte von verschiedenen Krystallisationsproben Verbrennungen aus. Dieselben ergaben auf aschefreie Substanz berechnet:

I. $0,2108 \mathrm{~g}$ Solanin gaben $0,4685 \mathrm{CO}_{2}=60,61$ Proc. $\mathrm{C}$ und $0,1575 \mathrm{H}_{2} \mathrm{O}=8,30$ Proc, $\mathrm{H}$ II. $0,2034 \mathrm{~g}=0,=0,4535==60,76==0,1560=-8,52=$ Zwenger und Kind fanden im Mittel $60,01==\quad 8,40==$ Hilger und Martin $==60,99==8,86={ }^{1}$ )

Einwirkung auf niedere Organismen.

Zur Untersuchung des Solanins auf seine Giftigkeit gegenüber niederen Organismen wurden als bequemste Objecte Darmparasiten des Frosches verwendet: Opalina, verschiedene Distomumformen, Amöben u. s. w. Eine Anzahl derselben, in der feuchten Kammer in lebhafter Bewegung begriffen, wurde durch Zusatz eines Tropfens 0,5 proe. neutraler Solaninlösung getödtet, und zwar stellte Opalina ihre Bewegungen im Momente des Zufliessens ein, obne sie wieder zu erlangen, die Amöben waren nach 2 Minuten unbeweglich, die Kokken und Bacterien mit Eigenbewegung in 15 Minuten. Ein Stiick-

1) Diese Zahlen babe ich selbst aus den $\mathrm{CO}_{2}$ - und $\mathrm{H}_{2} \mathrm{O}-\mathrm{Zahlen}$ der Analysen ron Hilger und Martin (Ann. chem. pharm. 195. Bd. S. 317) berechnet. Die Rechnungen dortselbst stimmen nicht vollkommen; ebenso scheint mir die Formel $\mathrm{C}_{42} \mathrm{H}_{87} \mathrm{NO}_{15}$ irrthümlich berechnet zu sein. Dieselbe würde 59,6 Proc. C und 10,3 Proc. H verlangen. Auch ist die ibid. für Acetylsolanin aufgestellte Formel $\mathrm{C}_{42} \mathrm{H}_{69}\left(\mathrm{C}_{2} \mathrm{H}_{3} \mathrm{O}\right)_{6} \mathrm{NO}_{15}$ damit unvereinbar. 
chen Rachenschleimhaut des Frosches mit lebhafter Flimmerbewegung des Epithels büsst dieselbe im Moment des Auftropfens von 0,5 proc. Solaninlösung ein. Das Solanin ist daher unzweifelhaft ein intensives Protoplasmagift.

$\mathrm{Zu}$ je $5 \mathrm{ccm}$ stark alkalischer Nährgelatine, bei $\mathbf{2 2}^{0}$ verflissigt, wurden je $0,05 \mathrm{~g}$ Solanin in 5 proc. kaum saurer Lösung gegeben, im Dampfkasten bei $100^{\circ} \mathrm{C}$. 1/2 Stunde lang sterilisirt, das in der Hitze ausgefallene Solanin durch wiederholtes vorsichtiges Verflüssigen wieder nahezu völlig gelöst und in die eine Gelatine mit Milzbrandsporen imprägnirte Seidenfäden, in die andere Micrococcus prodigiosus eingeimpft. 2 Controlgelatinen ohne Solanin wurden ebenso behandelt. In diesen fand bereits nach 2 Tagen Verflïssigung und lebhafte Entwicklung statt, während die Solaninculturen beide völlig steril blieben, auch beim wochenlangen Stehen.

Bacterienentwicklung wird also durch Solanin noch in einer Concentration von weniger als 1 Proc. gehemmt. Blut, welches ca. 0,2 bis 0,3 Proc. Solanin enthält, fault an der Luft nicht oder erst sehr spät. Schimmelpilze kommen in $0,5-1$ proc. Solaninlösungen noch fort, in concentrirteren nicht mehr.

Aufträufelung von 1 proc. Solaninlösung tödtet selbst zum Theil chitingepanzerte Thiere, z. B. kleine Arachniden, Isopoden, Chilognathen in 5-30 Minuten. Kleine Rundwürmer werden durch 0,5 proc. Solaninlösung zu ungemein lebhafter Bewegung gereizt, nach etwa $1 / 2$ Stunde hört die Bewegung allmählich auf und nach 40 Stunden sind die Würmer todt.

Das Solanin schädigt alles lebende Protoplasma, womit es in Berühung kommt, und bringt dasselbe noch bei grosser Verdünung $(0,1-0,5$ Proc.) zum Absterben.

\section{Wirkung auf BIut.}

Gelegentlich der ersten Versuche mit dem Williams'schen Apparat war beobachtet worden, dass die Blutmischung sofort nach dem Zusatz des Solanins durchsichtig; lackfarben wurde und nach kurzer Zeit einen schön violetten Ton annahm. Diese Wahrnehmung gab den Anstoss zu einer genaueren Verfolgung der Wirkungen, welche das Solanin auf das Blut und seine Theile ausübt. Ich untersuchte zunächst frisches, unverändertes Blut.

Lässt man aus der Carotis eines Kaninchens $10-20 \mathrm{ccm}$ Blut durch eine eingebundene Cantile in ein Bechergläschen fliessen, welches $0,5 \mathrm{ccm}$ einer 10 proc. Solaninlösung enthält, so wird das Blut sofort schwarzroth infolge des Austrittes von Hämoglobin ins Plasma. Während nun eine Controlportion in einem gleich grossen Bechergläschen mit $0,5 \mathrm{ccm}$ physiologischer Kochsalzlösung nach wenigen 
Minuten gerinnt, bleibt dieses Blut zähflüssig, ohne eigentlich zu gerinnen. Beim stundenlangen Ruhen gesteht es $\mathrm{zu}$ einer weichen, zerfliesslichen Gallerte, aus der sich erst nach weiteren 3-4 Stunden ein Blutkuchen abscheidet. Beim wochenlangen Stehen und Eintrocknen an der Luft wird das Blut theerartig, ohne zu faulen, während die Controlprobe bereits nach 24 Stunden in Fäulniss übergegangen ist. Eine verbältnissmässig grosse Menge von Solanin modificirt also den Gerinnungsvorgang normalen Blutes in der Weise, dass eine verspätete Fibrinausscheidung mit Auspressen von dunkelrothem Serum stattfindet. An frischem menschlichen Blut, aus einer Schnittwunde aufgefangen, wurde genau dasselbe beobachtet.

Geringe Mengen von Solanin dagegen beeinflussen die Gerinnung in umgekehrtem Sinne. Fängt man je $10 \mathrm{ccm}$ Blut aus der Carotis eines Kaninchens in 2 Reagircylindern auf, deren einer einen Tropfen einer 1 proc. Solaninlösung enthält, so gerinnt das Blut in diesem nach 1 Minute, ohne erkennbar lackfarben zu werden, während die Controlprobe noch dïnnflüssig ist und erst mehrere Minuten später gerinnt. Beim weiteren Stehen verhalten sich beide gleich.

Die Einwirkung auf die Blutzellen wurde an defibrinirtem Blute studirt, welches mit physiologischer Kochsalzlösung in verschiedenem Grade verdünnt war. Durch einen Nadelstich aus der Fingerspitze entnommenes Blut zeigt unter dem Mikroskop beim Zufliessenlassen eines Tröpfehens einer 1 proc. Solaninlösung unter das Deckgläschen in der ersten Minute alle denkbaren Formen der Poikilocytose. Die Zellen blassen schnell ab und nach 1 Minute sind nur noch schattenartige, zusammengeballte oder isolirte Stromata im gelblichen Felde sichtbar, nach wenigen Minuten sind die Contouren derselben auch bei schärfster Einstellung nicht unterscheidbar: die rothen Blutkörperchen sind zum Theil aufgelöst, zum Theil blos ausgelaugt. Vogeloder Froschblutkörperchen lassen bei langsamer Einwirkung des Solanins deutlich erkennen, wie neben der Entfärbung auch eine wirkliche Auflösung stattfindet. Die den Kern umgebende Protoplasmahülle bekommt Falten und Risse und schmilzt förmlich zusammen, so dass nach einer Einwirkung von wenigen Minuten nur noch der Kern allein oder mit einem kleinen anhaftenden Partikelchen der früheren Hülle sichtbar ist.

Die weissen Blutkörperchen werden in ihrer Form durch Solanin nicht verändert, doch wird der Kern auffallend deutlich, der Zellinhalt grobkörnig.

Auch bei allen anderen daranfhin untersuchten Thierspecies wird durch Solaninzusatz zum Blute das Hämoglobin aufgelöst. 
Die Mengen von Solanin, welche dazu nöthig sind, sind sebr gering.

Wenn man frisch defibrinirtes und filtrirtes Meerschweinchenblut mit der 100 fachen Menge 0,6 proc. Kochsalzlösung verdünnt und Proben von $100 \mathrm{ccm}$ mit $1 / 2,1 / 4$ oder $1 / 8$ com einer 0,5 proc. Solaninlösung schüttelt, so ergiebt sich:

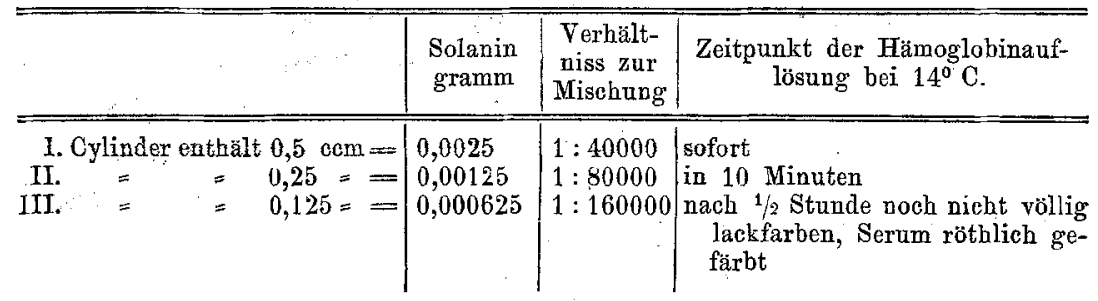

Die Concentration, in welcher eben noch innerhalb 15--30 Minuten der Blutfarbstoff den Blutzellen in beträchtlicher Menge entzogen wird, liegt also für Solanin nicht weit von $1: 100000$.

Eine undurchsichtige Mischung von $1 \mathrm{~cm}$ defibrinirten Meersehweinchenblutes und $100 \mathrm{ccm}$ physiologischer Kochsalzlösung wird sofort durchsichtig lackfarben, wenn man sie mit ein paar Solaninkrystallen schüttelt. Es genügt also die Spur Solanin, welche obne Säurezusatz sich in der Blutmischung löst, um Hämoglobin aufzulösen. Damit ist auch jeder Finwand abgeschnitten, es könnte vielleicht die bei allen Versuchen zur Auflösung des Solanins verwendete Citronensäure irgendwie frei werden und die Hämoglobinauflösung bewirken. Dagegen spricht auch das spectroskopische Verhalten des Solaninblutes.

Eine durch Solanin lackfarben gewordene Blutmischung zeigt frisch die beiden Streifen des Oxyhämoglobins wie normales Blut. Nach mehrstïndigem Stehen jedoch geht die hochrothe Farbe in eine blaurothe über und dann ist spectroskopisch das breite Band des reducirten Hämoglobins sichtbar. Methämoglobin tritt erst nach wochenlangem Stehen durch äussere Einflüsse in der Lösung auf, während Säuren schnell Methämoglobin bilden.

\section{Versuche an Fröschen.1)}

Resorptive Wirkungen.

Injicirt man einer Esculenta oder Temporaria 0,01 $\mathrm{g}$ Solanin in einen Lymphsack, so zuckt das Thier fast im Momente der Injection heftig zusammen und windet sich etwa 1 Minute vor Schmerz oder

1) Versuchsprotokolle als Belege der im Folgenden geschilderten Wirkungen konnten aus Rücksicht auf den beschränkten Raum hier, abgesehen von den Blutdruckversuchen, nicht beigefügt werden. Dieselben finden sich, wie bereits eingangs bemerkt, in meiner Dissertation. 
springt in sichtlicher Aufregung unter der Glasglocke hin und her. Nach wenigen Minuten jedoch ist es wieder ruhig und bleibt dann auffallend regungslos sitzen; die selten erfolgenden Willkürbewegungen sind deutlich matter als vorher; dem Umlegen auf den Rïcken wird nur geringer Widerstand entgegengesetzt und nach ea. 15 Minuten bleibt der Frosch umgelegt längere Zeit in Rückenlage, ohne active Bewegung, gewinnt jedoch noch von Zeit zu Zeit die Bauchlage mühsam wieder; selten wird jetzt noch ein Sprung versucht, der dann immer kraftlos und ungeschickt ausfällt. Nach 30 Minuten etwa gelingt es dem Frosch nicht mehr, die Rückenlage zu verlassen. Nach 40-45 Minuten hören die Willkürbewegungen vollständig auf.

Die Reflexe dagegen sind um diese Zeit nur wenig herabgesetzt; auf mechanische, chemische und elektrische, die Haut, die Cornea oder einen Nerven treffende Reize erfolgt prompte Reaction in nahen und entfernten Muskelgebieten. Erst allmählich werden sie schwächer und nach 2-3 Stunden erhält man selbst auf starke Reize nur noch selten eine Reaction.

Eine Extremität, deren zufübrende Arterie unterbunden oder die durch Massenligatur abgeschnïrt ist, wird von der Lähmung nicht ausgeschlossen.

Die Erregbarkeit der Muskeln und der Nervenstämme hat zur Zeit des Aufhörens der willkürlichen und reflectorischen Bewegungen noch nicht merkbar abgenommen. Die Bauchathmung wird 10-15 Minuten nach der Injection, wenn die willkürliche Beweglichkeit des Frosches noch annähernd normal ist, bereits aussetzend, die Respirations- und Schluckbewegungen erfolgen im Verlaufe der nächsten Stunde immer seltener, und etwa gleichzeitig mit dem Verlust der Willkürbewegung steht auch die Respiration still.

Motorische Reizerscheinungen, Krämpfe oder Zittern, konnten nie beobachtet werden. Bei mehreren Versuchen mit Injection von kleinen Dosen (3-5 mg) trat ebenfalls nichts dergleichen ein, sondern es entwickelte sich nur die Lähmung entsprechend langsamer.

20-30 Minuten nach der Subcutaninjection von Solanin zeigt sich an Fröschen eine auffallende Röthung der gesammten Hautoberfläche, herrührend von der durch das Gift bewirkten Hämoglobinauflösung; auch Rothfärbung des Plasmas und der Lymphe tritt ein. Die Röthe nimmt im Verlaufe der Vergiftung bis zum Tode zu. Gleichzeitig mit der Umgebung der Hautgefässe durchtränkt sich auch der Inhalt der Mundhöhle mit gelöstem Hämoglobin, auch Diapedese von rothen Blutkörperchen in die Mundhöhle, den Magen und Darm findet, wie sich bei der Section zeigt, ziemlich reichlich 
statt. Post mortem zeigen sich Nieren und Darm äusserst hyperämisch, sonst nichts Auffallendes.

Das Herz schlägt noch nach dem Verlust der Willkürbewegung ziemlich unverändert in Betreff der Pulsfrequenz, höchstens etwas weniger ausgiebig als vorher. Erst nach $1-1^{1 / 2}$ Stunden werden die Contractionen langsamer als vorher, die Ventrikelsystole erscheint verlängert, die Diastole wird kürzer und unvollständiger. Der völlige Stillstand tritt erst nach dem Erlöschen der Reflexe ein, bei $0,02 \mathrm{~g}$ nach $1 \frac{1 / 2}{2}-2$ Stunden, bei $0,01 \mathrm{~g}$ nach 4-6 Stunden. Der Ventrikel ist blutleer und blass, aber trotzdem auffallend schlaff und welk, während die Vorhöfe, deren Thätigkeit meist erst nach der des Ventrikels erlischt, weit diastolisch, mit deutlich lackfarbenem Blute gefüllt sind.

Die bisherigen Beobachtungen stehen, abgesehen von der bisher ïbersehenen Blutveränderung, im Wesentlichen in Uebereinstimmung mit jenen von Balmañya und Husemann. Sie ergeben eine centrale, vom Gehirn zum Rückenmark absteigende Lähmung, an welche sich später auch die Lähmung des Herzens anschliesst.

Um die Einwirkung des Solanins auf das Froschherz genauer zu verfolgen, habe ich eine Reihe von Versuchen am isolirten Herzen mittelst des Williams'schen Apparats angestellt.

Als Durchströmungsfliussigkeit wurde ein Gemisch von 1 Theil defibrinirten und filtrirten Rinderbluts und 2 Theilen einer 0,6 proc. Kochsalzlösung benutzt.

Bei einigen Versuchen wurden die bekannten Williams'schen Membranventile probeweise durch andere, nach meiner Angabe 1) gefertigte Ventile ersetzt, die in nebenstehender Figur (in $1 / 2$ natiirl. Gr.) abgebildet sind.

Jedes Ventil besteht aus 2 Glasröhren, welche an einem Ende auf einander geschliffen, am anderen Ende verjüngt sind, zusammengesteckt also wie eine Pipette aussehen. An einer Verjtingungsstelle ist ein kleiner hohler Glaskegel genau eingeschliffen. Dieser ist beim Einflussventil luftleer und schwimmt in der Flüssigkeit; beim Ausflussventil wird er mit so viel Quecksilber gefüllt, dass er gerade etwas specifisch schwerer ist als die Blutmischong und in dieser untersinkt.

Die Ventile werden parallel nebeneinander mit vertical gestellter Längsaxe befestigt. Ist nach Einschaltung derselben der ganze Apparat luftfrei gefiullt, was sehr leicht gelingt, so functionirt derselbe völlig zufriedenstellend. Die Ventile sprechen leicht an und schliessen gegen die durch das Froschherz erzengten Druckdifferenzen vollständig ab; grössere (ïber $100 \mathrm{~mm} \mathrm{Hg}$ ) gleichen sich sehr langsam aus; doch beeinträchtigt diese

1) Durch die Glasinstrumentenfabrik von J. Greiner in München. 
minimale Durchlässigkeit die Zwecke, welche die Ventile erfüllen wollen, nicht. Dieselbe bleibt anch beim sorgf ältigsten Einschleifen, da, um eine Adbäsion zu vermeiden, die Glaskegel nicht eingefettet werden dürfen.

Befestigung und Reinigung der Ventile macht keine Schwierigkeiten, und da sie ganz aus Glas bestehen, sind sie im Gegensatz zu den Membranventilen nnveränderlich.

Die Erscheinungen sind verschieden, je nachdem das Solanin der Flüssigkeit hinzugesetzt wird, in welche das Herz taucht, oder dem Durchströmungsblute.

Die Wirkung im ersteren Falle ist keine besonders starke. In einer 0,4 proc. Lösung schlägt das Herz stundenlang ohne wesentliche Schwächung. Steigt der Gehalt auf 1 Proc., dann tritt eine sofortige erhebliche Abnahme der absoluten Herzkraft und eine allmähliche des Pulsvolumens und der Pulsfrequenz ein. Nach circa 1 Stunde steht der Ventrikel still, er ist blauroth verfärbt, schlaff, wie macerirt; Physostigmin- oder Atropinapplication, sowie

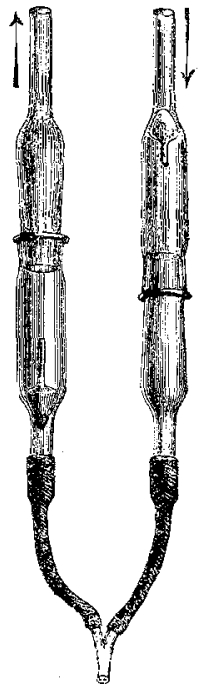
mechanische Reizung sind ohne Erfolg. Eine gleich vollständige Lähmung tritt in einer 2 Proc. Solanin enthaltenden Lösung nach 10 Minuten ein.

Viel energischer wirkt das Solanin, wenn man es dem Darchströmungs blute zusetzt.

Schon sehr kleine Mengen, 0,005 Proc., welche das Blut noch nicht vollständig lackfarben machen, bringen nach etwa $13 / 4$ Stunden unter sofortiger Abnahme der absoluten Herzkraft und allmählicher des Pulsvolumens und der Pulsfrequenz das Herz zum Stillstand. Dabei ist der Ventrikel blass und zusammengezogen. Bei sofortigem Durehleiten von normaler Blutmischung fängt das Herz nach kurzer Zeit wieder an zu schlagen und erlangt nach 1 Stunde fast die frühere Leistungsfähigkeit. Grössere Mengen, 0,05 Proc., welche das Blut schon vollständig lackfarben machen, bewirken Herzstillstand unter denselben Erscheinungen. Derselbe ist aber definitiv, durch Zuleiten von normalem Blut nicht wieder aufhebbar.

Noch grössere Mengen endlich, 0,1 Proc., wirken fast momentan; kaum sind die ersten Tropfen des lackfarbenen Blutes in den Ventrikel gelangt, so sinkt die Manometerfeder, noch einige wenige Pulse schreibend, auf die Abscisse berab und der Ventrikel steht eng zusammengezogen still. Mechanisehe Ausdehnung durch Erhöhung des 
venösen Drucks, Reizung des Herzmuskels durch Physostigmin und Lähmung der Hemmungsganglien durch Atropin, sowie Durchleiten normalen Blutes sind erfolglos:

Das Solanin wirkt also von innen etwa $100 \mathrm{mal}$ so giftig auf das Herz als von aussen.

Diese Thatsache' legt den Gedanken nahe, die Wirkung von innen sei eine indireete, durch die Blutveränderung, welche das Solanin bewirkt, hervorgebrachte. Man könnte denken, durch die Zugabe von Solanin zum Durchströmungsblut wird dieses lackfarben, damit wird dem Herzen seine Nährlösung verdorben, vielleicht entstehen dabei Herzgifte, vielleicht ist das lackfarbene Blut nicht im Stande, genügend Sauerstoff zuzuführen. Allein alle diese Vermuthungen wurden durch einen Versuch widerlegt, wo das Herz in Durchströmungsblut, welches durch Gefrieren und Aufthauen lackfarben gemacht war, über 1 Stunde vollständig kräftig und normal schlug, sowie durch einen anderen Versuch, wo das Herz mit Kalbsblutserum arbeitete und sich von einer Vergiftung mit $3 \mathrm{mg}$ Solanin bis zum Stillstand, andauernd durch Ausspïlen mit Serum erholte. Dabei ist die Hämoglobinauflösung ausgeschaltet und trotzdem ist das Herz empfindlicher gegen Solanin, als mit der Blutmischung.

Der deletäre Einfluss auf das Herz kommt also dem Solanin als solchem zu; dasselbe wirkt lähmend auf das Herz ganz unabhängig von der Veränderung der Nährlösung.

Um den grossen Unterschied in der Wirkang von aussen und von innen za erklären, bleibt kaum etwas Anderes übrig, als anzunehmen, dass das Solanin von aussen schwerer in den Muskel eindringt, als von innen, dass es zusammen mit der Durchströmungs flïssigkeit von innen leicht in alle Theile des Herzmuskels gelangt und die der Innenwand näher gelegenen automatischen Herzganglien von innen leichter erreicht.

Mikroskopisch zeigen die Herzen wenig normales Gewebe mehr. Der Herzmuskel ist seiner Querstreifung grösstentheils beraubt, die einzelnen Primitivbündel schollig zerfallen, morsch und unelastisch. Dieser Befund allein zeigt, dass der Herzstillstand bei Solaninvergiftung auf einer idiomusculären Herzparalyse beruht. Weder Lähmung der Hemmungsganglien durch Atropin, noch Muskelreizung durch Physostigmin sind, wie erwähnt, im Stande, denselben aufzuheben.

Der momentan eintretende Stillstand bei Zugabe genïgender Dosen vom Blute aus lässt jedoch mit ziemlicher Sicherheit schliessen, dass gleichzeitig mit dem Herzmuskel auch die automatischen Herzganglien gelähmt werden. Die auffallende Erscheinung, dass 
bei acuter Solaninvergiftung der Ventrikel des Froschberzens eng: zusammengezogen, die Vorhöfe weit ausgedehnt still stehen, ist schwer erklärlich. Eine digitalisähnliche Wirkung ist nicht vorhanden, Druckerhöhung hat keine Wirkung. Eine der Lähmung vorausgehende Reizung ist meist nur angedeutet durch schnell voribergehende Verstärkung oder Beschleunigung weniger Pulse gleich nach der Zugabe von Solanin.

Man kann sich also denken, dass gleichzeitig mit der Lähmung die anatomische Veränderung der Muskelsubstanz, sei es Gerinnung; Schrumpfung oder Quellung, die Ausdehnung des Ventrikels schnell oder allmählich hindert, während die Vorhöfe mit ihrer diunnen Muskelwand trotzdem noch passiv ausgedehnt werden können.

Dem widerspricht der Umstand nicht, dass ein in Solaninlösung: eintauchendes Herz nicht derart zusammengezogen still steht, weil hierbei offenbar die Maceration in der verhältnissmässig concentrirten Lösung in Betracht kommt.

Oertliche Wirkungen.

Neben den als Allgemeinwirkungen zu bezeichnenden Symptomen der Solaninvergiftung lassen sich an Fröschen noch eine Reihe bisher nicht bekannter örtlicher Einwirkungen beobachten, denen die zunächst mit dem Gifte in Berührung kommenden Organe oder Zellen unterliegen. Dieselben erleiden hierbei eine zum Theil leicht, selbst mit blossem Auge erkennbare Structurveränderung, welche in mancher Beziehung dem Effect einer starken Säureätzung ähnelt, so dass dem Solanin zweifellos eine chemische Affinität zu den Eiweisskörpern der thierischen Zelle zugesprochen werden muss.

Frösche zeigen bei Subcutaninjection von 0,5-2 proc. Solaninlösungen zuvörderst äusserst energische Abwehrversuche und Schmer"äusserungen; diese hören jedoch 2-3 Minuten nach der Injection auf, und wenn man jetzt die stärksten elektrischen oder mechanischen Reize auf die Injectionsstelle und ibre nächste Umgebung einwirken lässt, so erfolgt auch nicht die mindeste Reaction mehr. Die Haut und die zunächst darunter befindlichen Theile sind, soweit sie von der Solaninlösung durchtränkt wurden, vollständig unempfindlich. Das Solanin ist also ein locales Anaestheticum, aber nur deshalb, weil es local abtödtet. Die durch Solanin hervorgerufene Anästhesie ist nicht mehr redressirbar, denn sie ist gleichbedeutend mit Nekrose. ${ }^{1}$ )

1) Beim Warmblüter zeigt sich ebenfalls die intensiv reizende, Entzündung und Schmerz erregende Wirkung, welche das Solanin auf Schleimhäuten, serösen Archiv f. experiment. Pathol. u. Pharmakol. XXVI. Bd. 
Als Symptom des intensiven Hautreizes, welchen das Solanin verursacht, stellt sich bald in der Umgebung der Injectionsstelle eine arterielle Entztundungshyperämie ein, welche durch Hämoglobinämie noch augenfälliger wird.

Wenn man einem Frosch unter die Haut eines Unterschenkels $3-5 \mathrm{mg}$ Solanin spritzt und den grössten Theil der injicirten Flüssigkeit, um möglichst die resorptive Wirkung hintanzuhalten, wieder ablaufen lässt, so ist nach 3-5 Minuten von der Gegend des Einstiches aus keine Reflexzuckung mehr auslösbar, die örtliche Anästhesie also vollkommen, während alle anderen Hautstellen normale Empfindlichkeit besitzen und die Extremität willkürlich auch gut beweglich ist. Die unter der Injectionsstelle gelegenen Nervenstämme und Muskeln behalten in den ersten Stunden ihre normale Erregbarkeit, während die Hautanästhesie andauert. Nach 24 Stunden jedoch sind auch diese gegen chemische und elektrische Reize vollkommen nnerregbar, dunkelroth verfärbt und geschwellt. Das Bein wird beim Springen schlaff nachgeschleppt.

Dieses Verhalten veranlasste mich, die Einwirkung des Solanins auch an ausgeschnittenen Nerven und quergestreiften Muskeln zu prüfen.

Bei Application einer 0,5 proc. Solaninlösung auf das centrale Ende des Ischiadicus am Nervmuskelpräparat zeigen sich nur Andeutungen von Muskelzuckungen, und der Nerv ist nach 5-10 Minuten völlig unerregbar. Bei der Einwirkung einer 0,25 proc. Lösung zeigt sich eine primäre Reizung des Nerven in lebhaften Zuckungen der zugehörigen Muskeln; gleichzeitig erscheint die Erregbarkeit des Nerven etwas erhöht. Nach etwa 1/4 Stunde schlägt dann die Reizung in Lähmung um und der Nerv stirbt schnell ab.

Frisch herauspräparirte Musculi gastrocnemii von Fröschen ver lieren nach 10 Minuten langem Liegen in 0,25 proc. Solaninlösung: ihre Erreg barkeit vollständig, ohne sichtbar vorhergehendes Reizstadium. Gleichzeitig sind dieselben ihrer Querstreifung vollkommen beraubt und bieten mikroskopisch ein ähnliches Bild wie die mit Solanin vergifteten Froschherzen. Dieselben sind ferner, wenn sie 15 Minuten in der Lösung gelegen haben, derart brüchig,

Häuten, sowie auf der blossgelegten eutis entfaltet. - Auf die Conjunctiva einer Katze gebracht verursachen 2 Tropfen einer 1 proc. Solaninlösung auhaltendes Wischen, Zukneifen der Lider, Thränenfluss, Röthung und Schwellung der Bindehaut; alle diese Symptome gehen jedoch in einigen Stunden vorüber. Die Pupille bleibt unverändert. - Träufelt man in eine kleine frische Schnittwunde 3 bis 4 Tropfen einer 1 proc. Solaninlösung, so stellt sich nach wenigen Secunden ein intensives, brennendes Schmerzgefühl ein. Dasselbe hält über $1 / 2$ Stunde an. Sensibilitätsschwächung in der Umgebung tritt nicht ein. Die Wunde heilte per primam. 
unelastisch und förmlich macerirt, dass sie sich ausserordentlich leicht zerquetschen und zerzupfen lassen. Der Verlust der Querstreifung und der schollige Zerfall der Primitivbündel lässt sich auch unter dem Mikroskop im Entstehen beobachten.

\section{Versuche an Säugethieren.}

Die Wirkungen des Solanins auf Säugethiere sind in hohem Maasse bestimmt durch die Applicationsweise des Giftes. Am energischsten wirkt die

directe Einverleibung in das Blut.

Werden 1-2 proc. neutrale Lösungen von Solanin in physiologischer Kochsalzlösung in dem gewöhnlich bei Injection ins Blut eingehaltenen Tempo langsam und unter geringem Druck in die Vena jugularis externa von Kaninchen injicirt, so tritt, kaum dass 10 bis $20 \mathrm{mg}$ ins Blut gelangt sind, der Tod fast noch während der Injection unter Dyspnoe und tonisch-klonischen Krämpfen von mässiger Heftigkeit ein. Die Respiration steht während eines tonischen Krampfes der Thorax- und Bauchmusculatur in Exspirationsstellung still. Gleichzeitig wird der Herzstoss unfühlbar. Manuelle künstliche Respiration ist erfolglos. Bei sofortiger Eröffnung der Brust- und Bauchböhle bewegt sich das Herz noch ganz schwach; die Peristaltik ist verstärkt, überall venöse Stauung, Nerven und Muskeln reizbar, das Serum hellroth gefärbt durch aufgelöstes Hämoglobin.

Dieser plötzliche Tod unter allen Zeichen der Erstickung legte den Verdacht nahe, es könnten durch das Solanin ausser der Hämoglobinauflösung noch Gerinnungen im circulirenden Blute veranlasst werden und dadurch Thrombosen und Embolien entstehen. Dieser Verdacht bestätigte sich indessen nicht. Erstens wurde bei 5 Versuchen, wo unmittelbar auf die Injection von Solanin der Tod folgte, $n$ i e trotz sorgfältigsten Suchens, besonders in Gehirn und Lungen, eine Embolie gefunden, und zweitens fand ich, dass es auch bei Fröschen gelingt, durch entsprechend kleinere Dosen, wenn man sie direct ins Blut injicirt, sofortigen Tod, d. h. Aufhören der willkürlichen Bewegungen, Athmungs- und Herzstillstand herbeizuftuhren.

Es muss daher der Tod eine directe Wirkung des Solanins sein.

In erster Linie ist es wohl das Respirationseentrum, das der Lähmung unterliegt. Unzweifelhaft erfahren aber auch die Circulationsorgane eine schwere Schädigung; denn es gelingt nicht, durch sofort vorgenommene künstliche Respiration das Leben der Thiere zu ver. längern. 
Eine genaue Analyse dieser Wirkungen ist bei der Raschheit, mit der sie ablaufen, nicht möglich. Um diese zu erreichen, versuchte ich, verdiunnte, meist 0,2 proc. neutrale und frisch filtrirte Lösungen von Solanin in 0,6 proc. Kochsalzlösung äusserst langs a m aus einer Burette in die Vena jugularis einfliessen zu lassen.

Auf diese Weise gelang es in der That, den Eintritt des Todes hinauszuschieben, so dass nicht blos die Wirkungen auf das centrale Nervensystem und die Kreislaufsorgane genaner beobachtet werden konnten, sondern auch für die Ausbildung einer Reihe von Wirkungen in nicht unmittelbar lebenswichtigen Organen Zeit gegeben war.

25-30 mg pro Kilo einem Kaninchen derart ins Blut infundirt, tödten dasselbe nach $1 / 2-2$ Tagen, $30-40 \mathrm{mg}$ in $3-4$ Stunden, 40 bis $60 \mathrm{mg}$ in $1-2$ Stunden. Hunde gehen auf $40-60 \mathrm{mg}$ pro Kilo in eirca 12 Stunden zu Grunde.

Ein Kaninchen, welches eine intravenöse Vergiftung mit $20 \mathrm{mg}$ pro Kilo eben noch überstand, blieb hernach andauernd gesund. Das Solanin hat daher wahrscheinlich keine verspäteten Wirkungen, wohl weil es sehr bald, hauptsächlich durch die Nieren ausgeschieden wird.

Im Folgenden seien die Erscheinungen, welche bei solchen sehr langsamen Infusionen von $0,1-0,2$ proc. Solaninlösungen in eine Vene auftreten, beschrieben, und zwar der Reihe nach die Wirkungen auf die einzelnen Organe jedesmal im Zusammenbalt mit den betreffenden Sectionsbefunden.

Von Seite des Centralnervensystems macht sich nach mittleren Dosen ein anfängliches Reizungsstadium deutlich bemerkbar: anhaltende, schon während der Infusion als heftiger Tremor erscheinende fibrilläre Zuckangen in allen Muskelgruppen, späterhin klonische Krämpfe der Kiefer-, Hals- und Rückenmuskeln. Die letzteren erinnern an die bei Menschen zuweilen vorkommenden Nickkrämpfe (sog. Salaamkrämpfe) und sind wahrscheinlich, wie diese, auf eine Reizung der Accessoriuskerne mit klonischem Krampf der beiderseitigen Sternocleidomastoidei und Cucullares als Folge $\mathbf{z u}$ beziehen. Sie können auch in den Krampfpausen reflectorisch hervorgerufen werden. Der anfänglichen Reizung folgen sehr schnell die Symptome einer zunehmenden centralen Lähmung: Apathie, Schwerbeweglichkeit, Benommenheit des Sensoriums, Haltlosigkeit, Ausgleiten, Umsinken, endlich völliger Verlust der Willkürbewegung und Tod in tiefem Coma.

Die Sensibilität erleidet erst, nachdem die motorische Lähmung bereits deutlich ausgebildet ist, eine erhebliche Abnahme, die Reflexe 
sind bis kurz vor dem Tode erhalten; doch bedarf es mit der Zunahme der motorischen Lähmung immer stärkerer Reize, um dieselben, namentlich von der Haut aus, auszulösen. Die peripheren Nerven und Muskeln bleiben normal reizbar bis zum Tode.

Erwähnenswerth ist ferner eine nicht constante, aber manchmal sehr ausgesprochene Analgesie. Die Pupille wurde nie während der Vergiftung auffallend verändert gefunden. Als Agonieerscheinung trat wiederholt Nystagmus ein.

Bei der Section zeigten sich Gehirn- und Rïckenmarkssubstanz stets eher etwas anämischer als normal, die Meningengefässe und Sinus dagegen meistens stark von venösem Blute erfüllt. Zufälligerweise fand sich 2 mal an genau derselben Stelle unter dem Pons eine kleine, flache subarachnoideale Hämorrhagie; dieselbe war jedoch kaum im Stande, Compressionserscheinungen zu machen. Weder Blutungen noch embolische oder thrombotische Processe konnten im Gehirn, obwohl jedesmal darnach gesucht warde, nachgewiesen werden.

Die Temperatur wird in allen Fällen, wo überhaupt Vergiftungssymptome auftreten, constant erniedrigt, in einzelnen Fällen bis unter die Grenze, bei welcher der Warmblitterorganismus noch zu leben vermag; so einmal innerhalb nicht ganz 3 Stunden um $7^{\circ} \mathrm{C}$., von 38 auf $31^{\circ} \mathrm{C}$, einmal in der gleichen Zeit um $6^{\circ} \mathrm{C}$, , von 38 auf $32^{\circ}$ C. Dass daran nicht das vorïbergehende Aufbinden Schuld bat, beweist erstens der Umstand, dass bei einem normalen, mehrere Stunden lang aufgespannten Kaninchen, das ebenso in Watte eingepackt war, wie die Versuchsthiere, die Temperatur nụ um nicht ganz $1^{\circ}$ sank, zweitens die Thatsache, dass nach dem Losbinden der intravenös-vergifteten Thiere die Temperatur continuirlich weiter sank, endlich dass die Temperaturherabsetzung auch bei Solaninvergiftung: vom Unterhautzellgewebe, von der Bauchhöhle und vom Magen aus eintritt, wo keine oder nur kurze Befestigung stattfand.

Die Temperaturerniedrigung ist eines der charakteristischsten Symptome der Solaninintoxication, und der Thermometer giebt über den Grad und das Stadium derselben ebenso sicher Aufschluss, wie über den Grad des Fiebers.

Auch in nicht letal verlaufenden Fällen bezeichnet der tiefste Punkt der Temperatureurve den Höhepunkt der Vergiftung. Die Erholung hält gleichen Schritt mit dem Wiederansteigen der Temperatur.

Ueber die Ursachen dieser starken Temperaturerniedrigung vermag ich nichts Bestimmtes auszusagen, da ich nähere Untersuchungen 
darüber nicht angestellt babe. Ich halte es indess für kaum zweifelhaft, dass dieselbe in der Hauptsache eine directe Wirkung-des Solanins ist, und nicht eine indirecte, durch die Venosität des Blutes und die verminderte Muskelaction hervorgerufene, wie Husemann und Balmañy a meinen.

Bemerkenswerth ist, dass trotz hochgradiger Hyperämie aller Abdominalorgane die Temperatur in der Bauchhöhle, tief im Rectum gemessen (also annähernd die Bluttemperatur), continuirlich abnimmt.

Das Verbalten der Respiration bei intravenöser Solaninvergiftung ist nicht in allen Punkten constant. Die Athmungsfrequenz zeigt in der Mehrzahl der Fälle erst terminal eine erhebliche Abnahme. Zuweilen ist dieselbe anfangs beträchtlich gesteigert. Die Athmung wird während der Vergiftung fortschreitend angestrengter, namentlich im Exspirium, und dyspnoischer; kurz vor dem Tode erreichen die einzelnen Athemzïge (mittelst der Marey'schen Trommel aufgezeichnet) die 8-10 fache Tiefe der normalen. Arythmisch oder intermittirend wird die Athmung nur selten, dagegen treten nicht constant, aber sehr häufig während des Einfliessens der Solaninlösung kurze tonisch-klonische Krämpfe der Thorax- und Bauchmuskeln, auch des Zwerchfells in etwa minutenlangen Intervallen auf, deren Intensität zur Schnelligkeit des Einfliessens von Solanin in die Vene im geraden Verhältniss steht, und die mit grosser Wahrscheinlichkeit anf eine Reizung des Respirationscentrums bezogen werden miissen. Bei voribergehend etwas beschleunigtem Einfliessen treten dann sofort auch Krämpfe in den Nacken-, Rücken- und Extremitätenmuskeln auf, verbunden mit momentaner, oft bedeutender Pulsverlangsamung, die dann als Ausbreitung des Reizes auf das Vaguscentrum und die motorischen Centra aufzufassen sind. Mit der Beendigung der Infusion bören diese Krämpfe auf. Bei protrahirteren Fällen wird die Respirationsfrequenz gegen das Ende zu immer mebr verlangsamt, schliesslich erfolgen nur noch in Zwischenräumen von 5-10 Secunden laut tönende Inspirationen und gleich darauf steht die Athmung unter unbedeutenden Krämpfen der Hals- und Rückenmuskeln, seltener auch der Extremitäten still. Wenn der Tod noch während des Einfliessens oder unmittelbar darauf erfolgt, sind dagegen die agonalen dyspnoischen Krämpfe sehr heftig, bis zu mehrmaligem kurzdauerndem Opisthotonus gesteigert.

Der Respirationsstillstand ist, wie dies schon Balmañya und Husemann fanden, durch Lähmung des Respirationscentrums bedingt. Sehr wahrscheinlich jedoch ist die Dyspnoe bei vorgeschrittener 
Beiträge zur Kenntniss der Wirkungen des Solanins und Solanidins. 103

Solaninvergiftung, zam Theil auch durch die Kreislaufsstörungen und die Blutveränderung mit bedingt. Den Athmungsstillstand als alleinige, oder wenigstens hauptsächliche Todesursache hinzustellen, wie es bisher geschah, ist nicht zulässig, denn sofort eingeleitete künstliche Respiration vermag das Leben gar nicht oder höchstens nur wenige Minuten zu verlängern. Näheres hierïber enthalten die kymographischen Versuche.

Bei der Section fand sich in den Lungen ausser mehrfach vorhandenen subpleuralen Ekchymosen und kleineren Blutergtissen ins interstitielle und lufthaltige Gewebe, die für den Fortgang der Respiration wenig Bedeutung haben konnten, nichts Pathologisches. Embolien waren nie nachweisbar; der Inhalt der Bronchien war manchmal etwas Weniges mit Hämoglobin imbibirt. In den Pleurahöhlen fand sich bei mehreren Versuchen eine geringe Menge (circa $2-5 \mathrm{ccm}$ ) serös-sanguinolenter Flüssigkeit angesammelt.

Was die Veränderungen anlangt, welche die Functionen der Verdauungsorgane erleiden, so wurde beim Hund mebrmaliges Erbrechen beobachtet. Da dasselbe erst nach Ausscheidung von Solanin durch die Magenschleimbaut erfolgte, so ist es möglicherweise reflectorisch durch Reizung derselben hervorgerufen. Nar einmal beim Kaninchen traten Diarrhöen auf, stets aber waren durch die Bauchdecken hindurch lebhafte peristaltische Bewegungen zu fühlen.

Viel auffallendere und bisher nicht beobachtete Veränderungen wies der Sectionsbefund auf. ${ }^{1}$ )

Während der Magen, sowie der Blind- und Dickdarm in der Mehrzahl der Fälle annähernd normal und von Contentis ausgedehnt waren, in den anderen einen mässigen Grad von Entziundung aufwiesen, zeigte sich der Dünndarm regelmässig schon von aussen dunkelroth durch maximale Fuillung der Mesenterial- und Serosagefässe, manchmal auch mit wenigen kleinen subserösen Petechien besetzt. Als einziger Inhalt ist im ganzen Dünndarm constant eine mässige Menge schmutzig graurothen, nicht gallig tingirten, alkalischen Schleimes anzutreffen, der mikroskopisch aus massenhaft abgeschuppten Epithelien, mehr oder weniger veränderten rothen Blutkörperchen und einer verschieden grossen Menge von Lenkocyten und Spaltpilzen besteht. Je später der Tod erfolgt, um so mehr Lymphzellen sind darin nachweisbar. Beim Abstreifen desselben gehen mit grosser

1) Bei der Diagnose und Beurtheilung der pathologisch-anatomischen Befunde ertheilte mir wiederholt Herr Obermedicinalrath Prof. Bollinger in der zuvorkommendsten Weise Aufklärung. Ich spreche hiermit meinen verbindlichsten Dank hierfür aus. 
Leichtigkeit ganze Stiicke der Schleimhant mit. Diese selbst ist dunkelroth verfärbt, hochgradig verdickt und sammetartig geschwellt durch ein auch alle anderen Theile der Darmwand, besonders das submucöse Bindegewebe betreffendes acut-entziundliches Oedem. Dass es sich nicht um eine rein passive venöse Stauungshyperämie der Darmschleimhaut handelt, beweist vor Allem die bedeutende Epithelabschuppung, dann die bereits sehr frühzeitig eintretenden Blutungen durch Diapedesis ins Darmlumen und ins interglandaläre Stroma der Mucosa neben vereinzelten Hämorrhagien in verschiedenen Schichten der Darmwand, endlich die Schwellung und Prominenz der solitären und agminirten Follikel, welehe vollständig das Bild der markigen Infiltration wie im Typhusdarm der ersten Woche bieten, nur dass die Follikel nicht immer weiss, sondern gerade in den hochgradigsten Fällen roth geschwellt waren infolge von Diapedesisblutung in ibrer Umgebung, zum Theil anch durch Imbibition mit gelöstem Hämoglobin. Die Schleimbautgefässe zeigen namentlich wieder in der Umgebung der Plaques den böchsten Grad von Dilatation und Füllung. Dagegen konnte ich eine Thrombose der Darmcapillaren, wie sie bei anderen blutauflösenden Giften wohl vorkommt, nie mit Sicherheit nachweisen.

Das Bild einer solchen Schleimbautstelle aus dem Ileum eines Kaninchens nach dem Auftrocknen auf dem Objectträger mit Terpentinöl durchscheinend gemacht und in Canadabalsam gelegt zeigt Figur 1 (Taf. III u. IV) bei schwacher Vergrösserung. Das Präparat lässt deutlich die excessive Hyperämie der Schleimhant und blutige Infiltration der Peyer'schen Plaques erkennen. Dass die Gefässe an verschiedenen Stellen unverhältnissmässig erweitert erscheinen, rührt nur davon her, dass bei der Dicke des Präparats nicht alle Schichten der Darmwand gleichzeitig scharf eingestellt werden können. Die rothen Punkte versehieben sich bei veränderter Einstellung. Auf den ersten Blick könnte man đie Gefässe an jenen Stellen für thrombosirt halten. Der gelbe Grundton rührt von diffiuser Imbibition der Schleimhaut mit Hämoglobin her. Das mikroskopische Bild einer derartigen Sehleimbant auf in Alkohol gehärteten und mit Boraxcarmin gefärbten Schnitten ist ganz ähnlich, wie das von einem Hunde-Ileum bei intestinaler Solaninvergiftung (Fjgur 2, Taf. III u. IV).

Eines Urtheils über die letzten Ursachen dieser Veränderungen im Dünndarm muss ich mich noch enthalten; wahrseheinlich jedoch verdankt die Enteritis einer Ausscheidung von Solanin durch die Darmschleimhaut wenigstens zum Theil ibre Entstehung. Aus dem Inhalt des Dünndarms gelang es bei 2 maliger Untersuchung mit Sicherbeit Solanin zu isoliren, ebenso aus dem Erbrochenen.

Die neutralen oder sehwach alkalischen Massen wurden bei gelinder Wärme zur Trockne verdampft, der Rückstand mit absolutem Alkohol 
ausgekocht, der Auszug nach dem Verjagen des Alkohols mit schwach ammoniakalischem Wasser gewaschen. Der Rückstand war annähernd reines Solanin, das mit alkoholischer Schwefelsäure die charakteristische Rothfärbung gab.

Die Entstehung dieser Veränderungen bei eröffneter Bauchhöhle habe ich an einem Kaninchen beobachtet, welches bis an den Hals in physiologische Kochsalzlösung von constant $37,5^{\circ} \mathrm{C}$. getaucht war.

Unter dieser wurde die Bauchhöhle so weit eröffnet, dass fast der ganze Darm austrat. Derselbe zeigte sich normal im Zustande mittlerer Blutfüllung und Peristaltik. Vor dem Eintauchen war das Thier katheterisirt worden. Es wurden nun im Verlaufe von 11/2 Stunden im Ganzen $0,063 \mathrm{~g}$ Solanin in die Jugularis in 0,2 proc. Lösung infundirt.

Wenige Minuten nach Beginn des Einfliessens nahm die rosige Injection der Darmschlingen, besonders des $D$ ün $n$ darms, schnell zu und nach 15 Minuten war bereits ein excessiver Grad von Hyperämie aller Darmschlingen vorhanden, nach $1 / 2$ Stunde war die Färbung eine ganz diffuse, dunkel kirschrothe, auch am Blinddarm trotz der Pigmentirung deutlich wahrnehmbar. Gefässzerreissungen und Blutaustritte waren nicht sichtbar.

Gleichzeitig mit der Zunahme der Blutfüllung steigerte sich die Peristaltik rapid zur heftigsten Dysperistaltik. Der ganze Diunndarm gerieth in die intensivste Bewegung, die Dïnndarmschlingen bäumten sich übereinander und so schnell liefen die peristaltischen Wellen ab, dass die breiig-flüssigen, durch die Darmwand hindurch sichtbaren Contenta mit geradezu erstaunlicher Geschwindigkeit durch das Darmrohr gejagt wurden. Eine Zählung einzelner peristaltischer Wellen war unmöglich, es ging eine continuirlich in die andere über. Von Zeit zu Zeit jedoch verengte sich bald da, bald dort ein fingerdickes, von Speisebrei oder Gasen ausgedehntes Dünndarmstück auf eine Länge von $5-15 \mathrm{~cm} \mathrm{zu}$ einem bleistiftdicken Strang und verharrte 10-15 Secunden in diesem Zustand. Diese Ringmuskelkrämpfe brachten das Darmlumen völlig zum Verschwinden und pressten alles Blut aus bis zur totalen Anämie und wachsweissen Färbung der vorher und nachher dunkelrothen Darmschlinge.

Infolge dieser enorm gesteigerten Peristaltik war der ganze Dünndarm nach 30 Minuten vollständig leer von austreibbarem Inhalt, die Darmwand platt säbelscheidenförmig zusammengelegt und quergefältelt. Die Blutüberfüllung und Dysperistaltik betraf Duodenum, Jejunum und Ileum gleichzeitig und gleichmässig. Am Magen jedoch war, soweit sichtbar, Bewegung und Injection nicht abnorm, der Inhalt gasförmig.

Bedeutend geringer und seltener, aber auch erheblich gegen vorher verstärkt waren die Bewegungen des Blind- und Dickdarms. Es wurden während des Versuchs viel Kothballen und Darmgase entleert, aber keine diarrhoischen Fäces. Der Blinddarm füllte sich strotzend mit breiigen Contentis, ohne im Stande zu sein, dieselben auszutreiben.

Nach 1 Stunde hatte die Intensität der Darmbewegung bereits abgenommen, die Blutiiberfïllung war unverändert. Nach $5 / 4$ Stunden war 
die Herzaction bereits sehr arythmisch und unregelmässig; die allgemeinen tonischen Krämpfe wurden hänfiger und nach $11 / 2$ Stunden trat in einem kurzen Opisthotonus der Tod ein.

Sectionsbefund: Magen von Gasen mässig ausgedehnt, kaum pathologisch verändert, die Dünndarmschleimhaut in allen Theilen im Zustande der acuten parenchymatös-desquamativen, hämorrhagischen und folliculären Entzïndung, belegt mit einer dünnen Schicht von röthlichem Schleim, der hauptsächlich aus diapedesirten rothen Blutkörperchen und abgeschuppten Darmdrüsenepithelien besteht. Harnblase leer, Nieren dunkel rothbraun verfärbt, geschwellt, eben erkennbar gesprenkelt. Mikroskopisch: Hämoglobininfarct und acute Nephritis. Anurie.

Auf tiefgehende, bisher unbeachtete Veränderungen des Blutes und der Nieren lässt schon am lebenden Thiere das $V$ erhalten des Harns schliessen.

Der 15 Minuten bis 12 Stunden nach dem Beginn der Vergiftung entleerte Harn ist in fast allen Fällen dunkel blutroth gefärbt durch reichlich darin gelöstes $\mathrm{Häm}$ oglobjn, seltener auch Methämoglobin. Diese Hämoglobinurie ist eine Folge der Hämoglobinämie, der Auflösung von Blutfarbstoff im Blutplasma. Dass das Blut der intravenös mit Solanin vergifteten Thiere Blutroth aufgelöst enthält, davon kann man sich überzeugen, wenn man während oder kurz nach der Vergiftung aus einer Vene eine Blutprobe entnimmt, mit physiologischer Kochsalzlösung verdünnt und absetzen lässt. Die oben stehende Flüssigkeit ist dann stets mehr oder weniger roth gefärbt. Dagegen lässt sich spectroskopisch im Blute der Thiere niemals Methämoglobin nachweisen. Dieses muss daher, wenn es im Harn erscheint, erst beim Durchtritt durch die Niere oder nach erfolgter Ausscheidung entstanden sein.

An sonstigen abnormen chemischen Bestandtheilen enthält der Harn verschieden grosse Mengen von Eiweiss und in verhältnissmässig beträchtlicher Menge nnverändertes Solanin. Dasselbe ist bereits $1 / 2$ Stunde nach der Injection im Harn nachweisbar; einmal fanden sich noch nach 4 Tagen im normalen, nicht mebr hämoglobinhaltigen Harn Spuren davon.

Der Harn wurde alkalisch gemacht, fast zur Trockne verdampft, mit Weingeist ausgezogen, dieser verjagt und der Rückstand mit Wasser gewaschen. Derselbe war meist rein weiss und gab die Reactionen des Solanins, speciell die Färbungen mit concentrirten Mineralsäuren, deren Indentität mit den für Solanin charakteristischen öfters auch spectroskopisch nachgewiesen werden konnte.

Dagegen misslang der Nachweis von Solanidin im Harn der mit Solanin vergifteten Thiere stets oder es waren höchstens Spuren 
Beitrăge zur Kenntniss der Wirkungen des Solanins und Solanidins. 107

davon auffindbar, wenn man auf die angegebene Weise verfuhr und hernach den Rückstand mit Aether auszog.

Ausserdem enthält der Harn abnorme morphologische Bestandtheile.

Nicht constant, aber in vielen Fällen findet sich darin eine geringe Menge rother BIutkörperehen, meist nicht völlig entfärbt und in verschiedenem Grade difformirt.

Am sichersten jedoch lassen anf einen pathologischen Zustand der Nieren die constant auftretenden, in manchen Fällen massenhaft vorhandenen granulirten Cylinder schliessen. Daneben erscheinen meist noch wenige hyaline, mit Epithel bedeckte und durch Hämoglobin gefärbte Cylinder und Hämoglobin in Schollen und Körnchen.

Bei der Section finden sich die Nieren bei Hunden, Katzen und Kaninchen, abgesehen von den Ausnahmefällen, wo keine Hämoglobinurie eintrat, tief rothbraun, entweder gleichmässig oder grossfleckig gefärbt; oft sind sie ausserdem durch multiple dunklere Punkte, Blutergüsse ins Parenchym, gesprenkelt. Auf dem Durchschnitt ist die normale Streifung und Abgrenzung der Mark- und Rindensubstanz scharf sichtbar. Stets ist bedeutende Hyperämie vorhanden.

Mikroskopisch lässt sich schon am frischen Zupfpräparat ein zumeist durch alle Theile der Niere gleichmässig ausgebreiteter Hä moglobininfarct erkennen, an gefärbten Schnitten zeigt sich derselbe noch deutlicher.

Figur 3 u. 4 (Taf.III u. IV) sind zwar Abbildungen von Solanidinnieren, doch ist typisch dasselbe Bild an den Nieren der mit Solanin vergifteten Thiere zu sehen. Die genauere Beschreibung derselben siehe bei Solanidin.

Es sind ferner alle Zeichen einer frischen parenchymatösen Nephritis vorhanden, die in der Mehrzahl der Fälle einen hämorrhagischen Charakter hat. Daher die Albuminurie und Cylindrurie.

Die Ursache der Nephritis ist zweifellos das Solanin selbst, welches nachweisbar die Niere passirt. Das gelöste Hämoglobin allein vermag wobl kaum entzündungserregend zu wirken. Zudem tritt die Nephritis auch auf, wenn keine Hämoglobinurie vorhanden ist. Cylindrurie und Albuminurie hat bereits Clarus bei Solaninvergiftung vom Magen aus beobachtet; derselbe vermochte jedoch anatomisch keine Nephritis zu finden.

Zur Entwicklung hyperplastischer oder degenerativer Veränderungen in der Niere war bei den tödtlich verlaufenden Fällen keine Zeit gegeben. 
In einem Falle, wo der Tod durch intestinale Vergiftung 8 Tage nach dem Aufhören der đurch intravenöse verursachten Hämoglobinurie erfolgte, war ausser geringen Resten des Hämoglobininfarcts und theilweiser, offenbar frisch entstandener trïber Schwellung der Nierenepithelien nichts Pathologisches in der Niere zu entdecken, weil mit der innerhalb 24 Stunden fast vollendeten Ausscheidung des Solanins auch die Entzündungsursache aufgehört hatte, die beginnende Nephritis sich zurüekbilden, der Hämoglobininfarct grösstentheils ausgespült werden konnte.

Vielleicht gelingt es, durch längere Zeit hindurch fortgesetzte Injectionen von kleinen Mengen Solanin ausgebildete Formen von Nephritis zu bewirken.

Die Veränderungen, welche die Kreislaufsfunctionen durch Solanin erleiden, zeigten sich bei den einzelnen Versuchen mit kymographischer Aufzeichnung derselben in der Hauptsache constant. Nur diese constant wiederkehrenden Erscheinungen sind im Folgenden erwäbnt.

Einen bedeutenden Einfluss iubt unverkennbar die Schnelligkeit des Einfliessens. Beschleunigt man dasselbe, wenn auch nur sehr mässig, so beginnt der Blutdruck (in der Carotis gemessen) sofort rasch zu sinken und wiirde alsbald die Abscisse erreichen, wenn nicht schleunigst das Einfliessen sistirt oder verlangsamt würde, wie sich auch aus den Versuchen mit rascherer Injection von Solaninlösungen ergab. Geschieht dies noch rechtzeitig, dann erbebt sich der Blutdruck wieder zu seiner vorigen Höhe. Eine Infusionsgeschwindigkeit von $2-3 \mathrm{ccm} 0,2$ proc. Solaninkochsalzlösung $=4-6 \mathrm{mg}$ pro Minute wirkt bereits derart stürmisch. Gelangen nicht mehr als 1 bis $11 / 2 \mathrm{ccm}=2-3 \mathrm{mg}$ pro Minute in die Vene, so lassen sich ziemlich bedeutende Mengen Solanin (in 1 Stunde bis $\mathrm{zu} 40 \mathrm{mg}$ pro Kilo) einfübren, ohne dass sich bedeutende constante Veränderungen im Verhalten von Blutdruck und Herzthätigkeit einstellen. Es zeigt sich nur eine mässige Verminderung des Druckes und der Pulsfrequenz, die bis unmittelbar vor dem Ende bei beiden Factoren böchstens $1 / 3$ der ursprünglichen Höhe beträgt. Die Erregbarkeit des vasomotorischen Centrums (gepriuft durch Respirationsunterbrechung und sensible Reizung), sowie die Leistungsf ähigkeit des Herzens (geprifft durch digitale Compression der Bauchaorta) nimmt bis kurz vor dem Eintritt des Todes nicht erheblich ab.

Erst wenn fast die ganze Menge Solanin eingeflossen ist, die bei langsamer Infusion den Tod des Thieres in $1 / 2-1$ Stunde bewirkt (im Durchschnitt 40-50 mg pro Kilo), beginnt der Druck rasch, innerhalb 1-3 Minuten auf die Abscisse abzusinken; Unterbrechung der Respiration und Compression der Bauchaorta erhöhen denselben 
alsdann sebr wenig oder gar nicht mehr. Es ist also vasomotorische Lähmung und Herzschwäche eingetreten.

Beim curarisirten und ansgiebig ventilirten Thier verschwinden die Pulselevationen entweder gleichzeitig mit dem Absinken des Blutdruckes auf Null oder seltener unmittelbar hernach. Am nicht curarisirten Thier vermag sofort nach dem Respirationsstillstand eingeleitete ausgiebige künstliche Respiration ein Wiedererscheinen von Pulselevationen nicht zu bewirken. Es kann also kein $Z$ weifel sein, dass das Herz leistungsunfähig ist. Vollständig gelähmt ist es alsdann noch nicht, denn stets zeigt bei sofortiger Thoraxeröffnung das Herz noch einige Minuten lang spontane Znckungen. Dieselben sind jedoch derart schwach, langsam und in den meisten Fällen arythmisch und ungleichmässig, dass sie für die Circulation unmöglich noch einen Effect haben können. Nach 15 Minuten lassen sich höchstens noch an den Herzohren minimale Bewegungen wahrnehmen.

Wie weit die beschriebenen Erscheinungen anf directer Wirkung des Solanins auf die Kreislaufsorgane beruben und wie weit es sich um mittelbare Wirkung, bedingt durch die Blutveränderung und die mannigfaltigen Störungen in anderen Organen handelt, muss ich dalingestellt sein lassen.

Der Sectionsbefund der Thiere, welche zu den kymographischen Versuchen gedient hatten, zeigte ebenso wie bei den meisten anderen intravenös mit Solanin vergifteten Thieren ausser den bereits beschriebenen charakteristischen Veränderungen in Darm und Nieren auch Extravasate und durch Hämoglobin dunkelroth gefärbte Transsudate in der Bauchhöhle, den beiden Pleurahöhlen und im Herzbeutel, welche - besonders die manchmal recht beträchtlichen im Herzbeutel - gewiss nicht gleichguiltig für die Circulation waren. Das Endocard wies hänfig eine gleichmässige röthliche Imbibition als Folge der Hämoglobinämie auf. Mikroskopisch liess sich in manchen Fällen in den dem Endocard zunächst gelegenen Theilen des Herzmuskels eine stellenweise Verwischung der Querstreifung, Quellung and wellige Difformation der Primitivbündel nachweisen, in anderen Fällen wurde vergebens darnach gesucht. Unter dem Endocard und ebenso unter dem visceralen Blatte des Pericard fanden sich in mehreren Fällen frische kleine Blutaustritte, ebenso wie in anderen serösen Häuten und im Parenchym vieler Organe, besonders häufig in den Lymphdrüsen; nie aber liess sich, obwohl die röthliche Verfärbung den Verdacht auf Entzïndung erregte, ein sicheres Zeichen von Endocarditis nachweisen, ebensowenig capillare Embolien. 


\section{Belege.}

1. Kaninchen, $2200 \mathrm{~g}$, tracheotomirt. Respiration mit der Mareyschen Trommel aufgezeichnet. Im Ganzen $25 \mathrm{ccm} 0,2$ proc. Solaninlösung $=0,05 \mathrm{~g}$ Solanin in die linke Jugularis infundirt.

\begin{tabular}{|c|c|c|c|c|}
\hline Zeit & 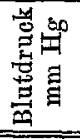 & 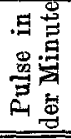 & 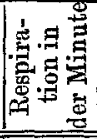 & Bemerkungen \\
\hline $3 \mathrm{~h} 17 \mathrm{~m}$ & 95 & 220 & 68 & Normaler Blutdruck. \\
\hline $3 \mathrm{~h} 19 \mathrm{~m}$ & 117 & 92 & - & Respirationsunterbrechung. \\
\hline $3 \mathrm{~h} 20 \mathrm{~m}$ & 97 & 164 & 60 & Beginn des Einfliessens. \\
\hline $3 \mathrm{~h} 22 \mathrm{~m}$ & 76 & 152 & 72 & Pulse verstärkt; leichte Krämpfe. \\
\hline $3 \mathrm{~h} 27 \mathrm{~m}$ & 83 & 146 & 64 & Pulselevationen erhöht. \\
\hline $3 \mathrm{~h} 30 \mathrm{~m}$ & 63 & 156 & 64 & Bis jetzt $20 \mathrm{mg}$ Solanin. \\
\hline $3 \mathrm{~h} 33 \mathrm{~m}$ & 79 & 152 & 64 & \\
\hline $3 \mathrm{~h}$ & 155 & 72 & & $\begin{array}{l}\text { Respirationsunterbrechung; grosse Pulselevationen, } \\
\text { Einfliessen sistirt. }\end{array}$ \\
\hline $3 \mathrm{~h} 38 \mathrm{~m}$ & 53 & 56 & 36 & Wiedereinfliessen, grosse Pulselevationen, Krämpfe. \\
\hline $9 \mathrm{~m}$ & 29 & 60 & 0 & Respirationsstillstand, $7 \mathrm{~mm}$ hohe Pulselevationen. \\
\hline $3 \mathrm{~h} 41 \mathrm{~m}$ & 10 & 120 & 0 & Pulse werden ganz gleichmässig allmählich kleiner. \\
\hline $2 \mathrm{~m}$ & 0 & 33 & — & Pulse noch eben angedeutet. \\
\hline
\end{tabular}

Künstliche Respiration erfolglos. Das Herz zeigt noch einige Minuten ganz schwache und langsame Zuckungen.

2. Kaninche n, 2050 g, tracheotomirt. Respiration mittelst Mareyscher Trommel aufgezeichnet. Im Ganzen $0,13 \mathrm{~g}$ Solanin intravenös.

\begin{tabular}{|c|c|c|c|c|c|}
\hline Zeit & 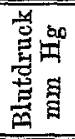 & 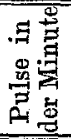 & $\begin{array}{l}\text { Respi } \\
\text { Athem- } \\
\text { ztige in d. } \\
\text { Minute }\end{array}$ & $\mid \begin{array}{c}\text { Höhed.Ele- } \\
\text { vationen } \\
\mathrm{mm}\end{array}$ & Bemerkungen \\
\hline $\begin{array}{l}11 \mathrm{~h} 37 \mathrm{~m} \\
11 \mathrm{~h} 38 \mathrm{~m}\end{array}$ & $\begin{array}{r}117 \\
95\end{array}$ & $\begin{array}{l}200 \\
224\end{array}$ & $\begin{array}{l}46 \\
48\end{array}$ & $\begin{array}{l}1 \\
2\end{array}$ & $\begin{array}{l}\text { Normaler Blutdruck. } \\
\text { Beginn des Einfliessens, Puls sehr } \\
\text { klein. }\end{array}$ \\
\hline $\begin{array}{l}11 \mathrm{~h} 42 \mathrm{~m} \\
11 \mathrm{~h} 44 \mathrm{~m} \\
11 \mathrm{~h} 50 \mathrm{~m} \\
11 \mathrm{~h} 52 \mathrm{~m} \\
11 \mathrm{~h} 54 \mathrm{~m} \\
11 \mathrm{~h} 56 \mathrm{~m}\end{array}$ & $\begin{array}{r}117 \\
90 \\
90 \\
110 \\
79 \\
90\end{array}$ & $\begin{array}{l}220 \\
232 \\
232 \\
232 \\
232 \\
232\end{array}$ & $\begin{array}{l}48 \\
52 \\
44 \\
56 \\
52 \\
56\end{array}$ & $\begin{array}{l}2 \\
2 \\
3 \\
3 \\
7 \\
9\end{array}$ & $\begin{array}{l}\text { Sistirung des Einlaufens. } \\
\text { Wiederbeginn des Einlaufens. } \\
\text { Einlauf sistirt. } \\
\text { Wiederbeginn des Einlaufens. } \\
\text { Respiration dyspnoiseh. Bisher } 0,07 \mathrm{~g} \\
\text { Solanin. }\end{array}$ \\
\hline $\begin{array}{l}12 \mathrm{~h}-\mathrm{m} \\
12 \mathrm{~h} 7 \mathrm{~m} \\
12 \mathrm{~h} 15 \mathrm{~m} \\
12 \mathrm{~h} 22 \mathrm{~m} \\
12 \mathrm{~h} 24 \mathrm{~m} \\
12 \mathrm{~h} 25 \mathrm{~m} \\
12 \mathrm{~h} 26 \mathrm{~m}\end{array}$ & $\begin{array}{l}90 \\
90 \\
77 \\
72 \\
54 \\
36 \\
0\end{array}$ & $\begin{array}{l}\bar{Z} \\
\overline{180} \\
172 \\
168 \\
-\end{array}$ & $\begin{array}{l}52 \\
52 \\
56 \\
44 \\
48 \\
60 \\
-\end{array}$ & $\begin{array}{r}9 \\
8 \\
10 \\
8 \\
8 \\
6 \\
-\end{array}$ & $\begin{array}{l}\text { Einlaufen sistirt, leichte Krümpfe. } \\
\text { Wiederbeginn des Einlaufens. } \\
\text { Krämpfe, Respiration höehst dyspnoisch. } \\
\text { Respirationsstillstand. Pulse nicht mehr } \\
\text { sichtbar. Kunstliche Respiration er- } \\
\text { folglos. Noch } 15 \text { Minuten lang mini- } \\
\text { male arythmische Bewegungen am } \\
\text { Herzen wahrzunehmen. }\end{array}$ \\
\hline
\end{tabular}


Beiträge zur Kenntniss der Wirkungen des Solanins und Solanidins. 111

3. Kaninchen, $2200 \mathrm{~g}$, tracheotomirt. Im Ganzen $45 \mathrm{ccm} 0,2$ proc. Lösung $=0,09 \mathrm{~g}$ Solanin intravenös.

\begin{tabular}{|c|c|c|c|}
\hline Zeit & $\begin{array}{c}\text { Blutdruck } \\
\mathrm{mm} \mathrm{Hg}\end{array}$ & $\begin{array}{l}\text { Pulse } \\
\text { in der } \\
\text { Minute }\end{array}$ & Bemerkungen \\
\hline $\begin{array}{l}4 \mathrm{~h} 47 \mathrm{~m} \\
4 \mathrm{~h} 48 \mathrm{~m} \\
4 \mathrm{~h} 50 \mathrm{~m} \\
4 \mathrm{~h} 53 \mathrm{~m} \\
4 \mathrm{~h} 54 \mathrm{~m} \\
4 \mathrm{~h} 59 \mathrm{~m} \\
5 \mathrm{~h} 9 \mathrm{~m} \\
5 \mathrm{~h} 16 \mathrm{~m} \\
5 \mathrm{~h} 17 \mathrm{~m} \\
5 \mathrm{~h} 18 \mathrm{~m} \\
5 \mathrm{~h} 21 \mathrm{~m} \\
5 \mathrm{~h} 22 \mathrm{~m} \\
5 \mathrm{~h} 24 \mathrm{~m} \\
5 \mathrm{~h} 28 \mathrm{~m} \\
5 \mathrm{~h} 30 \mathrm{~m}\end{array}$ & $\begin{array}{r}85 \\
\mathbf{1 1 7} \\
72 \\
\mathbf{1 1 5} \\
56 \\
67 \\
70 \\
72 \\
\mathbf{5 6} \\
\mathbf{9 2} \\
43 \\
\mathbf{9 2} \\
35 \\
7 \\
0\end{array}$ & $\begin{array}{r}256 \\
96 \\
232 \\
- \\
210 \\
212 \\
240 \\
240 \\
228 \\
\overline{212} \\
\overline{232} \\
-\end{array}$ & $\begin{array}{l}\text { Normaler Druck. Beginn des Einfliessens. } \\
\text { Respirationsunterbrechung } 50 \text { Secunden. } \\
\text { Aortencompression. } \\
\text { Sohnelleres Einfliessen. } \\
\text { Langsames Einfliessen. } \\
\text { Leichte Krämpfe. Dyspnoe. } \\
\text { Bisher } 0,06 \mathrm{~g} \text { Solanin. } \\
\text { Respiration } 64 \text {, dyspnoisch. } \\
\text { Aortencompression. } \\
\text { Leichte Krämpfe, Respiration } 60 . \\
\text { Aortencompression. } \\
\text { Krämpfe. Respirationsstillstand. } \\
\text { Aortencompression hebt auf } 25 \mathrm{~mm} \text {. } \\
\text { Pulse nicht mehr siohtbar. }\end{array}$ \\
\hline
\end{tabular}

Sofort eingeleitete nnd 10 Minuten fortgesetzte künstliche Respiration ist vollständig erfolglos. Das Herz bewegt sich noch circa 10 Minuten äusserst schwach und langsam, aber rythmisch.

4. Kaninch en, $2400 \mathrm{~g}$, tracheotomirt und curarisirt, künstliche Respiration; im Ganzen $0,055 \mathrm{~g}$ Solanin in 0,2 proc. Lösung von $35^{\circ} \mathrm{C}$. intravenös.

\begin{tabular}{|c|c|c|c|}
\hline Zeit & $\begin{array}{c}\text { Blutdruck } \\
\text { mm Bg }\end{array}$ & $\begin{array}{l}\text { Pulse } \\
\text { in der } \\
\text { Minute }\end{array}$ & Bemerkungen \\
\hline $\begin{array}{l}4 \mathrm{~h} 45 \mathrm{~m} \\
4 \mathrm{~h} 46 \mathrm{~m} \\
4 \mathrm{~h} 52 \mathrm{~m} \\
5 \mathrm{~h}-\mathrm{m} \\
5 \mathrm{~h} \quad 3 \mathrm{~m} \\
5 \mathrm{~h} \quad 9 \mathrm{~m} \\
5 \mathrm{~h} 12 \mathrm{~m} \\
5 \mathrm{~h} 14 \mathrm{~m} \\
5 \mathrm{~h} 15 \mathrm{~m} \\
5 \mathrm{~h} 17 \mathrm{~m} \\
5 \mathrm{~h} 19 \mathrm{~m} \\
5 \mathrm{~h} 20 \mathrm{~m} \\
5 \overline{\mathrm{h}} 23 \mathrm{~m} \\
5 \mathrm{~h} 25 \mathrm{~m}\end{array}$ & $\begin{array}{r}94 \\
74 \\
81 \\
71 \\
65 \\
81 \\
104 \\
95 \\
83 \\
\mathbf{1 0 3} \\
61 \\
40 \\
67 \\
31 \\
\mathbf{3 8} \\
8 \\
\mathbf{1 8}\end{array}$ & $\begin{array}{r}234 \\
236 \\
240 \\
248 \\
210 \\
198 \\
200 \\
84 \\
192 \\
204 \\
180 \\
172 \\
164 \\
- \\
- \\
-\end{array}$ & $\begin{array}{l}\text { Normaler Blutdruck. } \\
\text { Beginn des Einfliessens (etwas zu rasch). } \\
\text { Einfliessen verlangsamt. } \\
\text { Einfliessen etwas besehlennigt. } \\
\text { Einfliessen verlangsamt, } 0,035 \mathrm{~g} \text { Solanin. } \\
\text { Sensible Reizung. } \\
\text { Respirationsunterbrechung } 80 \text { Secunden. } \\
\text { Aortencompression. } \\
\text { Einlaufen sistirt. } \\
\text { Wiedereinlaufen. Pulselevationen versehwinden. } \\
\text { Aortencompression. } \\
\text { Aortencompression. } 2 \text { Minuten später ist keine } \\
\text { Bewegung am Herzen mehr wahrnehmbar. }\end{array}$ \\
\hline
\end{tabular}

5. Kaninehen, $2200 \mathrm{~g}$, tracheotomirt und curarisirt. Künstliche Respiration. Im Ganzen 0,091 g Solanin, theils 0,1-, theils 0,2 proc. Lösung in die Vena jugularis. 


\begin{tabular}{|c|c|c|c|}
\hline Zeit & $\begin{array}{c}\text { Blutdruek } \\
\text { mm Hg }\end{array}$ & $\begin{array}{l}\text { Pulse } \\
\text { in der } \\
\text { Minute }\end{array}$ & Bemerkungen \\
\hline $\begin{array}{l}5 \mathrm{~h} 38 \mathrm{~m} \\
5 \mathrm{~h} 40 \mathrm{~m} \\
5 \mathrm{~h} 45 \mathrm{~m} \\
5 \mathrm{~h} 50 \mathrm{~m} \\
5 \mathrm{~h} 58 \mathrm{~m} \\
6 \mathrm{~h} 3 \mathrm{~m} \\
6 \mathrm{~h} 12 \mathrm{~m} \\
6 \mathrm{~h} 15 \mathrm{~m} \\
6 \mathrm{~h} 18 \mathrm{~m} \\
6 \mathrm{~h} 19 \mathrm{~m} \\
6 \mathrm{~h} 20 \mathrm{~m}\end{array}$ & $\begin{array}{l}87 \\
91 \\
86 \\
80 \\
66,5 \\
57 \\
62 \\
57 \\
46 \\
64 \\
25\end{array}$ & $\begin{array}{r}180 \\
48 \\
220 \\
220 \\
160 \\
140 \\
150 \\
130 \\
90 \\
50 \\
-\end{array}$ & $\begin{array}{l}\text { Normaler Blutdruck. Beginn des Einfliessens. } \\
\text { Respirationsunterbrechung. } \\
\text { Bisher } 0,015 \mathrm{~g} \text { Solanin. } \\
\text { Pulselevationen verstärkt. } \\
\text { Bisher } 0,063 \mathrm{~g} \text { Solanin. } \\
\text { Respirationsunterbreehung. } \\
\text { Pulselevationen verstärkt. Temperatur } 36,2^{\circ} \mathrm{C} \text {. } \\
\text { Bisher } 0,087 \mathrm{~g} \text { Solanin. } \\
\text { Pulse infolge Gerinnung nicht mehr aufgezeichnet. } \\
\quad \text { Tod. Temperatur } 34,5^{\circ} \mathrm{C} \text {. }\end{array}$ \\
\hline
\end{tabular}

Am Herzen sind noch einige Minuten lang äusserst schwache und unregelmässige Zuckungen wahrzunehmen; nach 5 Minuten nur noch an den Herzohren.

6. Katze, $3000 \mathrm{~g}$, tracheotomirt und curarisirt, künstliche Respiration. Im Ganzen $0,08 \mathrm{~g}$ Solanin in 0,4 proc. Lösung in die Vena cruralis dextra; zeitweilig verhältnissmässig schnelles Einfliessen.

\begin{tabular}{|c|c|c|c|}
\hline Zeit & $\begin{array}{c}\text { Blutdruck } \\
\mathrm{mm} \mathbf{H g}\end{array}$ & $\begin{array}{l}\text { Pulse } \\
\text { in der } \\
\text { Minute }\end{array}$ & Bemerkungen \\
\hline $\begin{array}{c}5 \mathrm{~h} \quad 7 \mathrm{~m} \\
5 \mathrm{~h} 10 \mathrm{~m} \\
5 \mathrm{~h} 15 \mathrm{~m} \\
5 \mathrm{~h} 17 \mathrm{~m} \\
5 \mathrm{~h} 19 \mathrm{~m} \\
5 \mathrm{~h} 20 \mathrm{~m} \\
5 \mathrm{~h} 21 \mathrm{~m} \\
5 \mathrm{~h} 22 \mathrm{~m} \\
5 \mathrm{~h} 23 \mathrm{~m} \\
5 \mathrm{~h} 24 \mathrm{~m} \\
5 \mathrm{~h} 25 \mathrm{~m} \\
5 \mathrm{~h} 26 \mathrm{~m} \\
5 \mathrm{~h} 27 \mathrm{~m} \\
5 \mathrm{~h} 28 \mathrm{~m} \\
5 \mathrm{~h} 30 \mathrm{~m} \\
5 \mathrm{~h} 31 \mathrm{~m} \\
- \\
- \\
5 \mathrm{~h} 32 \mathrm{~m} \\
-\end{array}$ & $\begin{array}{r}76 \\
68 \\
\mathbf{1 4 6} \\
67 \\
25 \\
74 \\
41 \\
74 \\
45 \\
56 \\
22 \\
38 \\
29 \\
\mathbf{4 0} \\
\mathbf{4 0} \\
\mathbf{4 1} \\
31 \\
18 \\
9 \\
\mathbf{4} \\
-\end{array}$ & $\begin{array}{l}198 \\
196 \\
\mathbf{1 6 8} \\
192 \\
186 \\
192 \\
180 \\
180 \\
192 \\
120 \\
162 \\
- \\
162 \\
180 \\
180 \\
190 \\
185 \\
185 \\
160 \\
- \\
-\end{array}$ & $\begin{array}{l}\text { Normaler Blutdruck. } \\
\text { Respirationsunterbrechung, } \\
\text { Beginn des Einfliessens. } \\
\text { Schnelles Einfliessen. } \\
\text { Langsames Einfliessen. } \\
\text { Kräftige Pulselevationen. } \\
\text { Schnelleres Einfliessen. } \\
\text { Dikrotie. Bisher } 0,04 \mathrm{~g} \text { Solanin. } \\
\text { Curve unregelmässig. } \\
\text { Respirationsunterbrechung } 45 \text { Secunden. } \\
\text { Puls aussetzend. } \\
\text { Pulselevationen werden fortschreitend kleiner. } \\
\text { Einfliessen sistirt. } \\
\text { Pulse nicht mehr sichtbar. } \\
\text { Das Herz zeigt noch } 2 \text { Minuten lang äusserst } \\
\text { schwache und unregelmässige Zuckungen. }\end{array}$ \\
\hline
\end{tabular}


Injectionen von Solanin in die Peritonealhöhle von Kaninchen gemacht. Dieselben gehen bei Anwendung von 1/2-1 proc. Lösungen durch $37 \mathrm{mg}$ pro Kilo in 4 Stunden, durch $23 \mathrm{mg}$ pro Kilo in 7 Stunden zu Grunde.

In den ersten Minuten nach der Injection macht sich die ausserordentlich heftige Reizung des Bauchfells, welche das Solanin bewirkt, geltend. Dieselbe bringt einen förmlichen Shock hervor mit bedeutender Athembeschleunigung, Pulsverlangsamung und scheinbar völligem Collaps, so dass die Thiere 5-10 Minuten nach der Injection noch nicht im Stande sind, aufrecht zu sitzen und den Kopf zu erheben, sondern wie gelähmt erscheinen.

Erst nach etwa 1/2 Stunde, wenn diese Erscheinungen zurückgegangen sind, tritt die Wirkung des Solanins deutlich hervor. Diese zeigt sich während des Lebens hauptsächlich in Störungen von Seite des Centralnervensystems. Das Sensorium erscheint bei den Thieren, vielleicht infolge des anfänglichen Shocks, von Anfang an stärker benommen, als bei intravenöser Vergiftung. Dieselben sitzen mit halbgeschlossenen Augen fast ohne willkürliche Bewegung und reagiren fast gar nicht auf äussere Reize. Dagegen treten wenige Stunden nach der Vergiftung klonische Krämpfe, besonders in der Hals- und Rückenmusculatur auf, welche bis zum Tode des Thieres in immer kleineren Pausen und immer gesteigerter Intensität wiederkehren. Die Temperatur sinkt ununterbrochen im Verlaufe der Vergiftung, die Respiration wird zunehmend dyspnoischer, der Puls schwächer, in den letzten 10-15 Minuten unfühlbar. Die centrale Lähmung führt schliesslich zum Umsinken des Thieres und der Tod erfolgt in tiefem Coma. Bei vorgeschrittener Vergiftung ist in einer Blutprobe aufgelöstes Blutroth nachweisbar. Gleichwohl tritt dasselbe nicht in den Harn über, offenbar weil die verhältnissmässig geringe Menge noch innerhalb des Organismus verarbeitet werden kann.

Der Sectionsbefund entspricht den Symptomen während des Lebens. Die wichtigste Veränderung, welche sich vorfindet, ist eine hämorrhagisch-exsudative Peritonitis, welche zwar so frisch war, dass das Peritoneum selbst kaum verändert erschien, sich aber durch ein reichlich in die Bauchböhle ergossenes serös-zellig-sanguinolentes Exsudat zu erkennen gab. Die Abdominalorgane, besonders die Nieren, waren sehr hyperämisch; Enteritis war nur bei einem Meerschweinchen, nicht bei Kaninchen vorhanden. Andere anatomische Veränderungen fehlten.

Bemerkenswerth ist, dass ein guter Theil des Solanins in der Archiv f. experiment. Pathol. u. Pharmakol. XXVI. Bd. 
Bauchhöhle liegen bleibt und im Exsudat noch nachweisbar ist, so dass also die Dosis letalis fuir die Vergiftung mit Solanin von der Bauchhöhle aus sich etwa in gleicher Höhe hält mit der für intravenöse Infusion verdünnter Solaninlösungen gefundenen, $=$ circa $25 \mathrm{mg}$ pro Kilo.

\section{Wirkung bei subcutaner Injection.}

Die Erscheinungen, welche nach subcutaner Injection von Solanin an Kaninchen zu Tage treten, haben bereits Husemann und Balmañya beschrieben. Ich habe mich daher nur auf wenige Versuche beschränkt. Dabei zeigte es sich, dass gerade die wichtigsten Wirkungen des Solanins, nämlich auf Niere und Dünndarm, nach subcutaner Injection des Giftes fast gar nicht zu Stande kommen, die Blutveränderung nur in geringem Grade. So erklärt es sich auch, dass Husemann und Balmañya, welche sich aussehliesslich der Subcutaninjection bedienten, auf diese Wirkungen des Solanins nicht aufmerksam wurden.

Wie es die genannten Autoren beschreiben, tritt hierbei die Wirkung auf das Centralnervensystem in den Vordergrund. Ihre Eintheilung des Verlaufes in 2 Stadien scheint mir nicht besonders glücklich gewählt; was Husemann und Balmañya als 2. (Krampf-) Stadium beschreiben, ist eben die Agone. Die von denselben als Merkmal des 2. Stadiums angefuihrte Mydriasis konnte ich nie beobachten.

Die tödtliche Dosis bei subeutaner Vergiftung mit Solanin beträgt für Kaninchen etwas über $200 \mathrm{mg}$ pro Kilo, ist also vom Unterhautbindegewebe aus etwa $10 \mathrm{mal}$ so hoch, als von der Bauchhöhle oder vom Blute aus. Das Solanin wird, je concentrirter die Lösung, um so schlechter von der Subcutis aus resorbirt; wahrscheinlich wird die Resorption durch die local bewirkte Gewebsreizung beeinträchtigt, welche bei der Injection dureh unzweideutige Schmerzänsserungen der Versuchsthiere, besonders lebhaft bei Meerschweinchen zum Ausdruck gelangt. Dosen unter $200 \mathrm{mg}$ pro Kilo bewirken ausser der örtlichen Reizung, welche sich je nach der Concentration der Lösung in mässiger Entzündung bis zu eitrig nekrotischer Zerstörung der nächstliegenden Gewebspartien äussert, nur geringe motorische Reizerscheinungen. Die Thiere bleiben andauernd normal. Bei tödtlicher Subcutanvergiftung mit Solanin beobachtet man als hauptsächlichste Symptome: progressive allgemeine Lähmung, Absinken der Temperatur, (von $40^{\circ}$ anf $31,5^{\circ}$ !) Dyspnoe und Herzlähmung; post mortem fand sich locale Entzündung des Unterhautzellgewebes, geringe Hämo- 
globinämie, Hyperämie der Nieren, Schwellung der Peyer'schen Plaques, sonst nichts Abnormes.

\section{Wirkung vom Magen aus.}

Bei Einfïhrung von Solanin in Substanz in den Magen von Thieren, welche brechen können erfolgt nach 15-20 Minuten Herausbeförderung der ganzen eingefiihrten Giftmenge durch heftige Brechbewegungen. Bei Einführung von Solaninlösungen mittelst Schlundsonde tritt dies sofort ein. Die Thiere bleiben alsdann normal. Verhindert man das Erbrechen durch Oesophagusligatur oder spritzt man Solanin Thieren in den Magen, welche nicht brechen, z. B. Kaninchen, so bedarf es beträchtlicher Dosen, um iiberhaupt Erscheinungen zu bekommen. Die Dosis letalis vom Magen aus beträgt für Kaninchen gegen $300 \mathrm{mg}$ pro Kilo; darauf erfolgt der Tod in cirea $12 \mathrm{Stun}$ den. Bei kleineren Dosen bleiben erhebliche Vergiftungssymptome völlig aus.

Bei 2 Kaninchen, welche durch interne Solaninvergiftung zu Grunde gingen, zeigte sich von Seite des Centralnervensystems eine allmählich zunehmende centrale Lähmung; vorausgehende motorisehe Reizerscheinungen waren kaum angedeutet, einmal war Analgesie vorhanden. Die Temperatur sank continuirlich, die Respiration wurde bald dyspnoisch, die Herzaction etwas verstärkt und verlangsamt. Das Blutplasma enthielt anfgelöstes Hämoglobin, doch war die Hämoglobinämie nicht bedeutend genug, um Hämoglobinurie zu veranlassen.

Das eine dieser Kaninchen bekam 2 Stunden nach der Injection profuse breiige Diarrhöen ohne Blutbeimengung, das andere nicht.

2 Hunde dagegen, denen Solaninlösung in den Magen injicirt wurde und bei denen durch Unterbindung des Oesophagus das Erbrechen verhindert war, zeigten ausser sehr reichlichen Diarrhöen keine Symptome, welche auf mehr als blosses Unbehagen deuteten. Bei "dem einen mit $100 \mathrm{mg}$ pro Kilo (im Ganzen $1,0 \mathrm{~g}$ ) vergifteten Hunde waren die Diarrhöen schleimig-flüssig, fast ungefärbt wie Reiswasserstible, bei dem anderen, weleher $70 \mathrm{mg}$ pro Kilo erhielt, ebenso, nur mit beträehtlicher Blutbeimengung. Nach 12 Stunden, als kein Erbrechen mehr zu befürchten war, wurde die Oesophagusligatur bei beiden gelöst. Die Hunde erholten sich allmählich, und da befürehtet wurde, dass bei allzu langem Zuwarten der voraussiehtlich wichtigste Befund, die Gastroenteritis, anatomisch nicht mehr diagnosticirbar sein werde, so wurden sie getödtet, und zwar der erstere 21/2 Tage, der letztere, bei dem die Diarrhöen länger anhielten, 8 Tage nach der Vergiftung. 
Der Darm der Fleischfresser ist entschieden empfindlicher gegen Solanin, als der der Pflanzenfresser. Dosen, die bei Kaninchen nicht nothwendig Diarrhoe (wohl aber den Tod) bewirken (440 mg), thun dies prompt bei $10 \mathrm{mal}$ so grossen Hunden obne bedeutende Allgemeinerscheinungen.

Entsprechend den Symptomen intra vitam ist der hauptsächlichste pathologisch-anatomische Befund eine hämorrhagische, namentlich folliculäre Gastroenteritis, sehr ähnlich derjenigen, welche auch bei Solaninvergiftung vom Blute und zuweilen von der Bauchhöhle aus zu Stande kommt. Nur einmal unter den 4 angestellten Versuchen, und zwar bei dem mit $70 \mathrm{mg}$ pro Kilo vergifteten Hunde, der 8 Tage nach der Injection sich erholt hatte und getödtet wurde, fanden sich keine erheblichen Zeichen von Gastritis - dieselbe hatte sich wahrscheinlich bereits wieder zurückgebildet -, sondern blos heftige Enteritis. In den anderen 3 Fällen war sowohl die Magen- wie die Darmschleimhaut gleichmässig oder fleckig geröthet, stark geschwellt und so briichig, dass beim Abstreifen des daranhaftenden Schleimes mit grosser Leichtigkeit ganze Fetzen derselben sich ablösten. Die Magen- und Darmwand war mehrfach von Hämorrhagien durchsetzt, die Peyer'schen Plaques geschwellt, so dass eine derartige Schleimhaut auf den ersten Blick einer granulirenden Wundfäche glich. Figur 2 (Taf. III u. IV) zeigt einen Schnitt (in Alkohol gehärtet und mit Boraxcarmin gefärbt) durch die Ileumschleimhaut des mit $100 \mathrm{mg}$ pro Kilo vergifteten Hundes 60 Stunden nach der Injection.

Man sieht multiple capillare (wahrscheinlich Diapedesis-) Blutungen ins interglanduläre Bindegewebe (dieselben erseheinen in der Abbildung gelb), in diesem, sowie zwischen der Drüsenschicht und Muscularis mucosae, ja bis tief in die Bindegewebsschicht unterhalb der letzteren, eine sehr bedeutende Anhäufung von Rundzellen, hauptsächlich in der Nähe der lymphoiden Elemente, aber auch diffus zerstreut in der Submucosa.

Wie viel von dieser rundzelligen Infiltration Folge der Entzündung und wie viel eine noch innerhalb der Grenzen des Normalen liegende Leukocytenansammlung ist, wage ich einstweilen nicht zu entscheiden. Bei Vergleichung einer Reihe von Präparaten der normalen Darmschleimhaut konnte ich nie eine derartige diffuse Lymphzellenanhäufung bemerken.

Ausserdem sieht man bei stärkerer Vergrösserung die Epithelzellen der Lieberktihn'schen Drüsen trüb geschwellt, das Epithel der Zotten vielfach defect.

Als Inhalt in Magen und Darm fand sich in den 3 Fällen, wo Diarrhöen auftraten, nur eine geringe Menge zähen alkalischen Schleims, der einmal Blut beigemengt enthielt. Im Mageninhalt war bei Kaninchen noch reichlich Solanin nachweisbar.

Ausgeprägte Nephritis war nicht vorhanden, obwohl sehr geringe 
Mengen Solanin im Harn nachweisbar waren. Es wurde offenbar die grösste Menge des Solanins per anum entleert.

Die Section ergab ausserdem multiple Blutaustritte in fast allen Organen, besonders den serösen Häuten, sonst nichts Pathologisches.

Das Solanin wirkt also vom Magen aus in erster Linie breehenerregend. Kommt es trotzdem zur Resorption und zu einer directen Einwirkung auf den Darm, so bewirkt es in demselben eine heftige acute Schleimhautentziundung, die sich nur langsam zurückbildet, und als Folge derselben profuse Diarrhöen. Ob die Gastroenteritis eine resorptive, vom Blut aus zu Stande kommende ist oder nur eine Folge der örtlichen Reizung, welche das direct in die Schleimhaut eindringende Solanin bewirkt, wage ich nicht zu entscheiden. Vermuthlich ist Beides combinirt.

Dass von der Magen- und Darmschleimhaut nach Eintührung in den Magen Resorption des Solanins stattfindet, beweist erstens die auftretende Hämoglobinämie and dann das Erscheinen von Solanin bereits in der 2. Stunde nach der Vergiftung im Harn. Die Magensaftsecretion scheint durch die Einspritzung von schwach saurer 1- bis 2 proc. Solaninlösung vermindert oder unterbrochen $\mathrm{zu}$ werden, denn der Mageninhalt der $1 / 2-8$ Tage nach der Vergiftung secirten Thiere reagirt entweder kaum sauer oder selbst alkalisch. Dieser Umstand kann zur Erklärung der Thatsache mit herangezogen werden, dass entgegen der Behauptung von Dragendorff und Renteln aus dem Solanin bei Einspritzung in den Magen kein oder nur spurenweise Solanidin abgespalten wird. Es lässt sich nämlich im Harn der intern mit Solanin vergifteten Thiere unverändertes Solanin neben Spuren von Solanidin nachweisen. Es gelang mir indessen auch durch normalen Magensaft nicht, die Spaltung des Solanins zu bewirken.

Eine Probe von $0,05 \mathrm{~g}$ Solanin wurde in $10 \mathrm{ccm}$ frischen, aus der Magenfistel eines grossen Hundes gewonnenen und filtrirten Magensaftes aufgelöst und 6 Stunden bei constant $38^{\circ} \mathrm{C}$. im Brutofen der Verdauung ausgesetzt. . Eine gleiche Probe wurde in $10 \mathrm{ccm} \mathrm{0,1} \mathrm{proc.} \mathrm{Salzsäure} \mathrm{ge-}$ löst, 3 Tropfen Pepsinglycerin zugegeben und ebenfalls 6 Stunden im Brutofen gelassen. Gleichzeitig wurde die Wirksamkeit des Magensaftes und des Verdauungsgemisches an Fibrinflocken geprifft, die bereits nach 1 Stunde in den beiden Controlgläsern bis auf Spuren aufgelöst waren. Nach 6 Stunden wurden die vollständig klaren Solaninlösungen aus dem Brutofen entfernt, mittelst Soda schwach alkalisch gemacht nnd mit Aether geschuittelt. Dabei entstanden jedoch schwer trennbare Emulsionen. In der obenstehenden Schicht klar abgesetzten Aethers waren minimale Spuren von Solanidin gelöst, die nach dem Verdunsten des Aethers mit einem Tropfen alkoholischer Schwefelsäure nur eben erkennbare Gelbfärbung gaben. 
Nun wurden beide Proben bei gelinder Wärme auf dem Wasserbade bis fast zur Trockne verdunstet, mit absolutem Alkohol in der Siedehitze behandelt und filtrirt, das Filtrat bis zur Entfernung des Alkohols erwärmt, der Riùckstand in Wasser vertheilt, filtrirt, mit Wasser gewaschen, in wenig heissem 90 proc. Alkohol gelöst. Beim Erkalten desselben schied sich das Solanin in langen glänzenden, farblosen Nadeln aus, und zwar wurden auf diese Weise $0,03 \mathrm{~g}=60$ Proc. der angewandten Solaninmenge krystallisirt wieder erhalten. Die Nadeln lösten sich leicht auf Zusatz von Citronensäure in Wasser auf, was Solanidin nicht thut, und gaben ebenso wie der ungefärbte Verdampfungsrüickstand der alkoholischen Lauge keine einzige Solanidinreaction, aber alle charakteristischen Solaninreactionen. ${ }^{1}$ )

\section{Solanidin.}

Das zu meinen Versuchen benutzte Solanidin, von Merck in Darmstadt bezogen, war zwar krystallisirt und völlig Solanin-frei, aber ziemlich stark gelb gefärbt. Das Präparat wurde erst aus Aether, dann aus einem Gemisch von gleichen Theilen absolutem Alkohol und Aether umkrystallisirt. Aus letzterer Lösung krystallisirte das Solanidin in farblosen Büscheln von bis zu $10 \mathrm{~cm}$ langen, vierseitig prismatischen, sehr elastischen, perlglänzenden Nadeln, vom Schmelzpankt $210^{\circ} \mathrm{C}$.

Herr Dr. J. Brandl ${ }^{2}$ ), Assistent am pharmakologischen Institut dahier, hatte die Freundlichkeit, den G- und H-Gehalt des Präparats zu bestimmen. Die Resultate der 2 Verbrennungen stimmen sogar besser zu der von $\mathrm{Hilger}$ und Martin aufgestellten Formel $\left(\mathrm{C}_{26} \mathrm{H}_{41} \mathrm{NO}_{2}\right)$, als die Analysen dieser Autoren selbst.

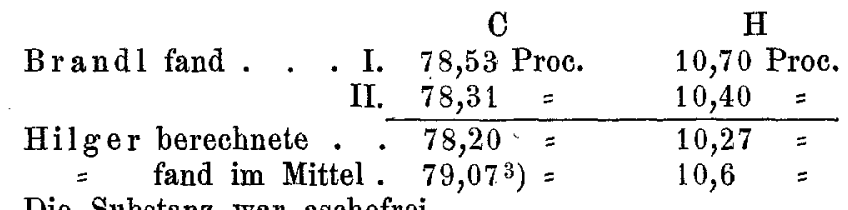

Die Substanz war aschefrei.

In kalter verdünnter Schwefelsäure oder Phosphorsäure ist etwas über 1 Proc. Solanidin löslich. Die Lösung reagirt merklich sauer. Zwenger und Kind, welche die Salze des Solanidins zuerst dargestellt und studirt haben, erhielten das neutrale schwefelsaure Salz

1) Eine röthlich-violette Lösung von Jod in Chloroform bräunte sich z. B. nicht damit, was sie nach meinen Beobachtungen bei Anwesenheit von Spuren Solanidin bereits thut.

2) Ich bin Herrn Dr. Brandl hierfür, sowie für seine sonstige mir im Verlauf der Untersuchungen oft bewiesene Gefälligkeit zu grossem Danke verpflichtet.

3) Dieses Mittel für $\mathrm{C}$ resultirt aus den 1. c. von Hilger und Martin angegebenen $\mathrm{CO}_{2}$-Zahlen; daselbst steht statt dessen 78,8 Proc. C. 
nie für sich, sondern stets zusammen mit 1, 2 oder 3 Aequivalenten des sauren Salzes. Alle, auch die neutralen Salze des Solanidins reagiren sauer. Dieselben sind gut krystallisirbar. Verdünnte Lösungen (unter 0,5 Proc.) kann man bis zur fast vollständig neutralen Reaction bringen, ohne dass sie sich trïben.

Die Lösungen fast aller Neutralsalze der Alkalien, alkalischen Erden und Metalle fällen das Solanidin noch aus sehr verdünnter wässriger Lösung vollständig oder fast vollständig aus, lassen jedoch das Solanin unverändert.

Wichtig für die Beurtheilung der physiologischen Wirkung des Solanidins ist sein bisher unbekanntes Verhalten gegen verdünnte Kochsalzlösung. Es gelingt nicht, durch Zusatz von Schwefelsäure oder Phosphorsäure das Solanidin mehr als spurenweise in physiologischer Kochsalzlösung aufzulösen. Durch Zugabe von 0,6 proc. Kochsalzlösung wird das mittelst Schwefelsäure in destillirtem Wasser aufgelöste Solanidin sofort fast vollständig undeutlich krystallinisch ausgefällt, aus phosphorsaurer, übrigens stets stärker sauer reagirender Lösung nach wenigen Minuten. War sehr wenig Kochsalzlösung zugegeben, so löst sich der Niederschlag beim schwachen Erwärmen voriibergehend wieder auf, um beim Erkalten sofort wieder auszufallen; sind etwa gleiche Theile 0,6 proc. Kochsalzlösung und $0,2-$ bis 1 proc. Solanidinlösung gemischt, oder ist noch mehr Kochsalzlösung zugegen, so entsteht und bleibt der Niederschlag auch in der Wärme. Wenn sich derselbe nach wenigen Minuten abgesetzt hat, lassen sich in der obenstehenden Flïssigkeit nur noch Spuren von Solanidin nachweisen; dieselbe reagirt nicht merklich saurer als vorher.

Diese meines Wissens keinem anderen bisher näher studirten Alkaloide oder Glykoside zukommende Eigenschaft ist zweifellos in hohem Maasse bestimmend für seine Wirkungen gegenüber den Flüssigkeiten und Geweben des Organismus. Auch der Umstand, dass die Gegenwart von Eiweiss die Fällung des Solanidins aus neutraler wässriger Lösung durch verdünnte Alkalien nicht hindert, wie es beim Solanin in geringem Grade der Fall zu sein scheint, ist in ähnlichem Sinne in Betracht zu ziehen.

Die Versuchsanordnung und Reihenfolge war bei den Experimenten mit Solanidin vollständig die gleiche wie bei den jeweils mit Solanin angestellten; es wurden $0,1-0,5$ procentige, annähernd neutrale, jedesmal frisch bereitete Lösungen von Solanidin in destillirtem Wasser angewendet; zur Lösung diente Schwefelsäure. Die nur in Einzelheiten von den bei Solanin beobachteten Erscheinungen abweichenden Resultate der Solanidinversuche machen es wünschens- 
wertb, das Hauptgewicht auf die Beschreibung der zwisehen beiden gefundenen Unterschiede zu legen und das bei sorgfältiger Vergleichung völlig Gleichartige nicht wiederholt zu schildern, sondern nur als solches zu constatiren.

Einwirkung auf niedere Organismen.

Die verschiedenen einzelligen und wenigzelligen Organismen, welche zur Prufung der Giftwirkung des Solanins dienten, unterliegen in ganz gleicher Weise der Einwirkung einer 0,5-1 proc. Lösung von schwefelsaurem Solanidin.

Die Flimmer- und Rotationsbewegungen der Opalina hörten im Momente des Einfliessens der Solanidinlösung in die fenchte Kammer auf, die Bewegung der Distomen und Amöben nach 2-5 Minuten, die der Kokken, Spirillen und Bacterien dagegen meist erst nach 1/2-1 Stunde. Spinnen, Fliegen u. s. w. gehen nach dem Eintauchen des Kopfes in Solanidinlösung in 10-20 Minuten zu Grunde. Solanidin ist also ein Protoplasmagift. Auf antiseptische Wirkung habe ich das Solanidin bisher nicht geprüft, weil es auf keine Weise gelang, dasselbe in Nährgelatine u. s. w. in Lösung zu erhalten.

\section{Einwirkung auf Blut.}

Das Solanidin ist ebenso wie das Solanin ein Blutgift. 0,5 proc. Solanidinlösung, mit friseh aus einer Schnittwunde vom Mensehen oder aus der Carotis eines Kaninchens aufgefangenem Blut im Verhältniss von 1:1 gemischt, verzögert die Gerinnung gegenüber der Controlprobe um 3-4 Minuten. Dann aber tritt die Gerinnung in gewöhnlicher Weise ein, nur ist das Serum roth gefärbt.

Dagegen konnte bisher eine Beschleunigung der Gerinnung bei Zusatz kleiner Mengen Solanidin nicht beobachtet werden. Solanidin giebt beim Zasammentreffen mit Blat einen Niederschlag; derselbe besteht jedoch nicht etwa aus gefällten Eiweisskörpern, sondern lediglich aus Solanidin. Giebt man zu einer Mischung von $1 \mathrm{ccm}$ Blnt (defibrinirt und filtrirt) mit $20 \mathrm{cem}$ physiologischer Kochsalzlösung $1 \mathrm{ccm} 0,5$ proc. Solanidinlösung, so sieht die Probe auf den ersten Blick nicht anders aus, als eine uur Vergleichung aufgestellte Controlprobe, sie wird nicht durchsichtig. Sieht man aber genauer zu, so lässt sich erkennen, dass die Undurchsichtigkeit nicht mehr auf der Suspendirung von rothen Blutkörperchen im ungefärbten Serum, sondern auf der Vertheilung feiner weisser Flocken im rothgefärbten Serum beruht. Filtrirt man jetzt die Flüssigkeit, so läuft als Filtrat rothes, lackfarbenes Serum durch, während auf dem Filter ein unge- 
färbter Niederschlag bleibt, der aus fast reinem Solanidin zum kleinsten Theil aus zusammengeballten, entfärbten Blutzellen besteht und aus Aether umkrystallisirt feine Nadeln liefert. - Das Solanidin ist im Stande, noch bei grosser Verdünnung die rothen Blutkörperchen aller darauf hin untersuchten Thierspecies zu entfärben und zu difformiren, nicht jedoch in einer Verdünnung, wo noch annähernd neutrale Reaction erreichbar ist, dieselben völlig aufzulösen.

Lässt man zu einem Tropfen durch Nadelstich aus der Fingerspitze entnommenen Blutes unter dem Mikroskop einen Tropfen 0,5 proc. Solanidinlösung fliessen, so beobachtet man die Entstehung eines aus stark lichtbrechenden, fein vertheilten Körnern bestehenden Niederschlags. Die Blutkörperchen blassen ab und nehmen, wie ganz regelmässig beobachtet wurde, ausnahmslos die Gestalt von hohlen Halbkugeln oder eingedrückten Gummiballen an. Ebenso verhalten sich die Blutkörperchen vom Kaninchen. Bei Vogel-, Frosch- und Fischblutkörperchen blasst zuerst die ovale Hülle ab und der Kern tritt stark lichtbrechend scharf hervor, dann quellen sie stark auf, die Hiulle bekommt Risse und Falten und es entstehen alle möglichen Formen von Poikilocyten.

In welcher Verdiinnung das Solanidin noch im Stande ist, den rothen Blutkörperchen Hämoglobin zu entziehen, wurde mit 0,5 proc. Solanidinlösung an Meerschweinchenblat geprü̈ft, das nach dem Defibriniren und Filtriren mit 100 Theilen physiologischer Kochsalzlösung verdünnt war.

Der Versuch ergab folgendes Resultat:

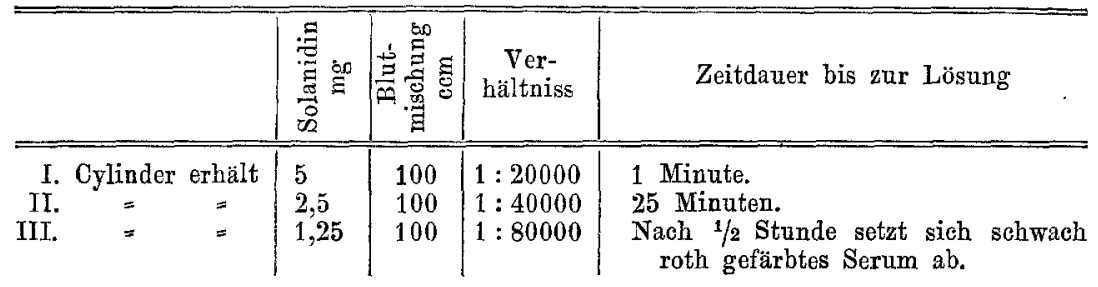

In allen 3 Cylindern hatte sich ein theils flockiger, theils pulveriger Niederschlag von Solanidin gebildet. Die Concentration, in der das Solanidin eben noch deutlich Hämoglobin auflöst, liegt also scheinbar etwas böher, als die für Solanin. Dies erklärt sich jedoch wahrscheinlich ebenso, wie die sonstige schwächere Wirkung im Vergleich mit Solanin durch die sofortige Ausfällung. Im Zusammenhalt damit erscheint die Fähigkeit des Solanidins, Hämoglobin aufzulösen, sogar noch grösser als die des Solanins.

Durch Solanidin lackfarben gewordene Blutmischungen behalten etwa 24 Stunden lang, obwohl sie dem Ansehen nach ihre Farbe 
bald bedeutend verändert haben und matt rothviolett aussehen, das Spectrum des Oxyhämoglobins; hernach entsteht reducirtes Hämoglobin, Methämoglobin erst nach mehreren Tagen.

\section{Wirkung auf Frösche.}

Spritzt man einem Frosch $2 \mathrm{cg}$ Solanidin in 0,5 proc. Lösung in den Rückenlymphsack, so erfolgt keine besonders heftige momentane Reaction, dagegen giebt sich während der ersten Minuten eine gewisse Aufregung durch rastloses Umherhüpfen des Frosches zu erkennen. Gleichzeitig jedoch gewinnt der Frosch, auf den Rücken gelegt, bereits die Bauchlage nicht oder schwer wieder. Nach etwa 10 Minuten bleibt der Frosch, auf den Rücken gelegt, ruhig liegen, geräth jedoch von Zeit zu Zeit spontan, besonders aber bei Berührung der Bauchhaut oder Erschütterung der Unterlage in eine Art Emprosthotonus mit spastischer Contraction der Pectoralmuskeln, der 10-20 Secunden anhält, worauf der Frosch wieder in die Rückenlage zuriicksinkt. Diese bei 2 Versuchen beobachtete Erscheinung scheint mir indess nicht auf einer krampferregenden oder reflexerhöhhenden Wirkung des Solanidins za beruhen, sondern ebenso wie das bei Solaninvergiftung beobachtete Herumgreifen mit allen 4 Extremitäten auf einer gleichzeitig mit der beginnenden Motilitätslähmung auftretenden Lähmung der Coordinationscentra, die allen intendirten Bewegungen eine unzweckmässige und sonderbare Form verleiht.

Nach 1-1 1/2 Stunden hüpft der Frosch, auf die Beine gesetzt, fort, aber ungeschickt und oft auf die Seite statt anf den Bauch. Im weiteren Verlauf der Vergiftung nimmt die centrale Lähmung zu, die Willkürbewegungen werden immer seltener und schwächer und hören nach 2-3 Stunden ganz auf; die Erregbarkeit der Muskeln, der Nervenstämme und Endigungen, des Rückenmarks (Quer- und Längsleitung) ist dann noch erhalten, aber erheblich abgeschwächt. Die Respiration wird bereits 15 Minuten nach der Injection verlangsamt und eigenthümlich krampfhaft im Exspirium, und hört ebenfalls nach 2-3 Stunden auf.

Das Herz schlug in allen Fällen noch nach Eintritt der Motilitätslähmung fort, aber frühzeitig verlangsamt, nach $4 \mathbf{- 5}$ Stunden aussetzend und schwach, und stand schliesslich in Diastole still. Ein durch Solanidin zum Stillstand gekommenes Froschherz sieht nicht so schlaff und macerirt aus, wie bei Solanin, trotzdem aber viel voluminöser, weil der Ventrikel bei Solanin constant mehr oder weniger stark zusammengezogen, bei Solanidin weit ausgedehnt ist. 
Der Stillstand wird durch Atropinaufträufelung nicht aufgehoben, Physostigmin brachte einmal nach dem Stillstand anfgeträufelt eine Anzahl schwacher Contractionen herror. Mechanisch war der Herzmuskel stets noch kurze Zeit nach dem Stillstand erregbar. Mikroskopisch war keine bedeutende Veränderung in demselben wahrzunehmen, nur waren die Kerne auffallend deutlich und scharf begrenzt sichtbar.

Centrale absteigende Lähmung, die auch das Respirationscentrum betrifft, ferner Lähmung der excitomotorischen Herzganglien und des Herzmuskels sind die Hanptwirkungen des Solanidins bei subcutaner Injection an Kaltbliutern. Die anfängliche Unrube deutet vielleicht auf eine initiale Reizung der motorischen Centra.

Kleinere Dosen, 3-4 mg wirken nar sehr langsam auf Frösche, die darnach in $4-5$ Tagen unter den beschriebenen Erscheinungen zu Grunde gehen.

Die Rothfärbung der Haut ist weit weniger ausgesprochen als bei Solanin. Bei der Section findet sich das Blut zum Theil lackfarben.

Durch Injection von $1 \mathrm{mg}$ Solanidin in die $\mathrm{Crural}$ vene eines Frosches wird sofortige centrale Lähmung und Herzstillstand in Diastole bewirkt. Durch mechanischen Reiz ist alsdann das Herz noch längere Zeit zu Contractionen zu bringen, Nerven und Muskeln sind normal reizbar, die Reflexe sehr herabgesetzt. Durch Aufträufeln von 20 Tropfen 0,5 proc. Solanidinlösung auf das freigelegte Froschherz kann man in wenigen Minuten Herzstillstand in Diastole bewirken (Solaninaufträufelung bleibt lange fast wirkungslos), ohne allgemeine Vergiftungssymptome. Dann ist das Herz noch mechanisch erregbar, aber Atropinaufträufelung erfolglos.

Die Allgemeinwirkung des Solanidins auf Frösche bei subcutaner Injection ist also von der des Solanins hauptsächlich dadurch zu unterscheiden, dass sie bei der gleichen Dosis von beiden sich langsamer entwickelt als bei Solanin, sicherlich weil das Solanidin in Berïhrung mit den Säften und Geweben des thierischen Körpers sofort, wenigstens zum Theil, gefällt wird. Es kann aber eben daraus mit einiger Wahrscheinlichkeit geschlossen werden, dass das Solanidin, welches ja, wie anzunehmen ist, den giftigen Atomeomplex des Solanins isolirt darstellt und daher stärker wirksam sein sollte, auch in der That giftiger ist als dieses, seine intensivere Giftwirkung jedoch infolge seiner Schwerlöslichkeit in den Flüssigkeiten des thierischen Organismus $\mathbf{z u}$ entfalten sehr gehindert ist. 
Die örtlichen Wirkugen des Solanins fehlen dem Solanidin so gut wie völlig. Die Injection verursacht den Thieren keinen Schmerz. Es entwickelt sich an der Injectionsstelle keine Hyperämie und auch keine locale Anästhesie. Wenn man einem Frosch unter die Haut eines Unterschenkels einige Milligramm Solanidin in 0,2 proc. Lösung spritzt und in der gleichen Weise, wie dies bei Solanin geschah, einen Theil der Lösung wieder auslaufen lässt, so wird die Sensibilität in der Umgebung der Injectionsstelle kaum merklich abgeschwächt und es tritt keine Entzïndung oder Gangrän des Gliedes ein wie bei Solanin.

Auf die peripheren Nerven and Muskeln hat das Solanidin in der Concentration, welehe ohne störende Nebeneinflüsse überbaupt noch anwendbar ist, keine erhebliche Einwirkung. Die Prüfung: wurde auf dieselbe Weise vorgenommen, wie bei Solanin. Auf den peripheren Stumpf des Ischiadicus wurden in steigender Concentration 0,2-1 proc. Lösungen einwirken gelassen. Die Muskeln blieben stets unbeweglich wie am Controlpräparat, die Erregbarkeit des eingetauchten Nervenstücks nahm zwar successive ab, aber es ist sehr wahrscheinlich, dass daran zum Theil das destillirte Wasser Schuld war. Sobald man den Nervenstumpf in die Solanidinlösung eintauchen lässt, bildet sich im Umkreise um denselben ein dichter weisser, feinpulveriger Niederschlag von Solanidin, dessen Ausbreitung genau die Diffusion zwischen dem flüssigen Inhalt des Nerven und der Solanidinlösung $\mathrm{zu}$ beobachten gestattet.

Frosehmuskeln in 0,5 proc. Solanidinlösung gelegt, erzeugen denselben Niederschlag, quellen aber nur darin auf, ohne in der ersten Stunde ibre Erregbarkeit ganz einzubiissen. Mikroskopisch findet sich dann die Querstreifung etwas verwaschen, die Kerne auffallend deutlich.

Um die Einwirkung von Solanidin auf das künstlich durchblutete Froschherz zu beobachten, wurde der Williamssche Apparat mit der bei den Solaninversuchen beschriebenen Modification benutzt. Die Versuchsanordnnng war ganz dieselbe, nur wurden blos $25 \mathrm{ccm}$ Durchströmungsfliissigkeit angewendet. Die Versuche zeigen, dass das Solanidin, trotzdem beim Zusatz desselben zu der Blutmischung sofort ein Niederschlag entsteht, in einer ursprünglichen Concentration von 0,04-0,06 Proc. eine Schwächung der Herzeontractionen und der absoluten Herzkraft, Verminderung der Schlagzahl und in circa 1 Stunde Stillstand in Diastole hervorbringt. Der Stillstand ist zuweilen kein definitiver, sondern noch nach längerer Zeit beginnt die Herzthätigkeit wieder, wahrscheinlich weil der 
grösste Theil des Solanidins ausgefällt ist. Die Erbolung tritt anch beim Durchleiten normalen Blutes ein.

So lange das Solanidin noch einwirkt, hebt weder Atropin, noch Physostigmin den Stillstand auf. Mikroskopisch zeigen die mit Solanidin vergifteten Herzen die Querstreifung des Muskels deutlich an vielen Stellen, namentlich in den centralen Theilen verwischt und die einzelnen Primitivbündel getrïbt, gequollen und geschlängelt; die peripher gelegenen Theile sind nicht oder kaum verändert.

\section{Wirkung auf Säugethiere.}

Wirkang bei directer Einverleibung ins Blut.

Gegen die Einfiuhrung von.Solanidin ins Blut sind zweierlei Einwände möglich: 1. „der im Blute durch Solanidin entstehende Niederschlag kann vielleicht capillare Embolien verursachen".

Dem ist entgegenzuhalten, dass der Niederschlag bei der Mischung , einer 0,2 proc. Lösung von schwefelsaurem Solanidin, wie sie stets angewandt wurde, mit Blut in so feiner Vertheilung herausfällt, dass er wohl zweifellos die Capillaren passirt. In der That wurden nie embolische Infarcte gefunden, obwohl stets darnach gesucht wurde.

Der 2. Einwand wäre: „Bei Einführung von destillirtem Wasser ins Blut kann auch hierdurch allein schon Hydrämie, Hämoglobinämie und deren Folgen erzeugt werden."

Dieses Bedenken ist zweifellos berechtigt und hielt mich auch ab, den Versuchen mit intravenöser Einführung von Solanidin eine grössere Ausdehnung za geben. Indessen war die Beimischung der Lösung zum Blute stets eine derart langsame und die infundirte Wassermenge im Verhältniss zur Blutmenge eine so mässige, dass die Blutverdünnung kaum einen Grad erreichen konnte, bei welchem Hämoglobin in bemerkenswerther Menge hätte aufgelöst werden können.

Die Symptome intra vitam und der Sectionsbefund bei der Infusion von Solanidin ins Blut decken sich so gut wie völlig mit den Erscheinungen bei Infusion etwa $1 / 2-1 / 3$ so grosser Dosen Solanin.

Von Seite des Nervensystems zeigen sich Tremor und leichte klonische Krämpfe, besonders der Rückenmuskeln als Reizerscheinungen; Schwerbeweglichkeit und progressive Abnahme der Motilität als centrale Lähmungserscheinungen bei erhaltenem Sensorium vollkommen wie bei Solanininfusion ins Blut. Alles, was dort darüber bemerkt ist, gilt in gleicher Weise auch für das Solanidin. Auch Analgesie wurde einmal bei der Katze in einem vorgeschrittenen Stadium der Vergiftung beobachtet. 
Continuirliches Sinken der Temperatur bis zum Tode ist ein constantes Symptom tödtlicher Solanidinvergiftung. Hier wie beim Solanin lässt sich der Grad und das Stadium der Vergiftung am besten am Thermometer erkennen.

Temperatursteigerung und Mydriasis, die von $\mathrm{Hus}$ emann und Balm a ñy als constant beschrieben werden, sah ich nicht eintreten, letztere auch agonal nicht. 5 Tropfen einer 1 proc. Solaninlösung auf die Conjunctiva einer Katze getrüufelt, hatten mit Ausnahme von etwas Zukneifen der Lider und Wischen keinen Effect. Weder Conjunctivitis noch Pupillenveränderung trat ein, auch nicht nach Stunden.

Die Respiration wird sehr bald dyspnoisch; bei acuter Vergiftung zeigen sich Thoraxmuskelkrämpfe und allgemeine dyspnoische, der Asphyxie vorangehende Krämpfe wie bei schnellerer Solaninvergiftung.

Nach dem Respirationsstillstand zuckt das Herz noch schwach und unregelmässig. Mehrmals wurde Hämoglobinämie und starke Hämoglobinurie, Methämoglobinurie and Cylindrurie beobachtet.

Die pathologisch-anatomischen Befunde sind im Wesentlichen wie bei Solanin: venöse Hyperämie aller, besonders der Abdominalorgane, Imbibitionsfärbungen und vereinzelte Hämorrhagien in verschiedenen Organen, hauptsächlich aber die auch bei Solanin beschriebenen Veränderungen in Nieren und Dünndarm in typischer Form.

Das Bild des Hämoglobininfarctes in der Katzenniere bei intravenöser Solanidin-Intoxication zeigt Figur 3 u. 4 (Taf. III u. IV).

Bei schwacher Vergrösserung sieht man auf in Alkohol gehärteten und mit Boraxcarmin gefärbten Schnitten die Lumina der Harnkanälchen ziemlich gleichmässig in der Rinden- und Marksubstanz mit Cylindern und Schollen von Hämoglobin ausgefüllt. Auf dem Querschnitt getroffen zeigt sich ein grosser Theil der Tubuli recti und contorti, auch der Sammelröhren durch Hämoglobincylinder dilatirt und verstopft, so dass man sich wundert, wie bei den Thieren, in der Regel wenigstens, keine Oligurie eintritt. Ausserdem zeigen sich bei schwacher Vergrösserung multiple, grössere und kleinere Blutergüsse, besonders in der Corticalis.

Das Protoplasma des Nierenparenchyms ist stellenweise diffus mit Blutfarbstoff imbibirt. Bei stärkerer Vergrösserung zeigt sich, dass die Epithelien der Harnkanälchen und der Bowmann'schen Kapseln sich im Zustande der truben Schwellung befinden. Das Protoplasma derselben ist staubig getriibt, die Kerne gequollen, die Lumina der Harnkanälchen, soweit sie nicht durch Hämoglobin erfitllt sind, verstrichen. Das Epithel der Bowmann'schen Kapseln ist zum Theil abgesehilfert, die Glomeruli sind auffallend zellreich. Im interstitiellen Bindegewebe ist stellenweise beginnende Kernvermehrung wahrzunehmen.

Die Nephritis ist bei Solanidin also mit den gleichen Symptomen und anatomischen Veränderungen verbunden wie bei Solanin. 
Da Solanidin in beträehtlicher Quantität im Harn nachweisbar war, ist wahrscheinlich auch die Solanidin-Nephritis durch Ausscheidung des Giftes mit dem Harn hervorgerufen. - Im Dünndarm fand sich ganz wie bei Solanin die charakteristische hämorrhagische, vorzugsweise folliculäre Schleimhautentzündung mit Diapedesisblutung ins Darmlumen, massenhafter Epithelabschuppung, ödematöser Schwellung und dunkelrother Färbung der Schleimhaut. -

In Betreff der Wirkungen von anderen Applicationsorten aus erwähne ich nur eine Vergiftung von der Bauchhöhle aus. Ein Kaninchen wurde durch $85 \mathrm{mg}$ Solanidin pro Kilo noch nicht getödtet. Die Symptome von Seiten des Nervensystems waren genau die bei der gleichen Applicationsweise von Solanin auftretenden. Andere Symptome fehlten.

Eine bei einem Meerschweinchen durch subcutane Injection von $130 \mathrm{mg}$ pro Kilo Solanidin bewirkte, nach 5 Tagen tödtliche Vergiftung war insofern von Interesse, als sie zeigte, dass das Solanidin sehr späte Wirkungen haben kann, was bei Solanin nie beobachtet werden konnte, die Erscheinungen waren typisch die der subcutanen Solaninvergiftung.

Bei der Einbringung von Solanidin in die Peritonealhöhle, ins Unterhautzellgewebe oder in Wunden macht sich keine locale Reizerscheinung bemerklich. Hierin ist der Hauptunterschied zwischen Solanin und Solanidin gegeben.

Die im Vorhergehenden geschilderten Eigenschaften des Solanins und Solanidins, vor Allem die bisher nicht beobachteten, nämlich die entzïndungserregende Wirkung auf Dünndarm und Nieren, die Hämoglobin-Auflösung und für Solanin noch die örtlich reizende Wirkung berechtigen dazu, die bisherige Stellung beider Gifte im pharmakologischen System zu ändern und denselben einen Platz anzuweisen nahe demjenigen, welchen die Gruppe der Sapotoxine (Quillajasäure1), Sapotoxin, Senegin, Cyclamin) einnimmt.

Das Solanin ist, wie es als basisches Glykosid chemisch eine Mittelstellung zwischen Alkaloiden und Glykosiden einnimmt, so auch pharmakologisch als ein Uebergangsglied zwischen diesen beiden Gruppen zu betrachten. Solanin und Solanidin sind - abgesehen vielleicht von Emetin und Sepsin, welche auch Enteritis bewirken -, die ersten bisher bekannten stickstoff haltigen Körper mit den Eigen-

1) R. Ko b ert, Ueber Quillajasäure. Dieses Archiv. XXIII. Bd. S. 233. 1887 u. Arbeiten des pharmakologischen Instituts zu Dorpat, herausgegeben von R. Kobert, Stuttgart 1888 . 
schaften eines Alkaloides, welche, in geringer Menge dem Blute beigemischt, schwere pathologisch-anatomische Veränderungen im thierischen Organismus hervorbringen.

Zum Schlusse sei es mir gestattet, meinem hochverehrten Lehrer, Herrn Prof. Dr. Tappeiner, für das sorgsame Interesse, die vielfache wirksame Anregung und thatkräftige Förderung, welche mir bei der Ausführung der vorliegenden Arbeit von seiner Seite unausgesetzt zu Theil wurde, meinen innigsten Dank auszusprechen.

\section{Literaturverzeichniss}

(chronologisch geordnet mit kurzer Inhaltsangabe).

\section{A. Botanische und chemische Literatur.}

(Die mit * bezeichneten Arbeiten konnten nicht im. Originale eingesehen werden.)

Defosses, Journal de pharmacie. Vol. VI. p. 374-376. 1820; Vol. VII. p. 414-417. 1821. Magendie, Vorschr. zur Bereitung und Anwendung einiger neuen Arzneimittel. Leipzig 1822. S. 157. Trommsdorff's Journal der Pharmacie. VI. Bd. S. 273. Berzelius' Jahresberichte. II. Bd. S. 114: Entdeckung eines Alkaloids (Solané) in verschiedeneu Organen von Sol. nigrum und Sol. dulcamara; Darstellungsmethode und Eigenschaften desselben; Nachweis der Giftigkeit.

Morin, Auffindung von Solanin in Solanum mammosum. Journal de chimie médicale. Vol. I. p. 84.1825.

Chevallier und Payen, Auffindung von Solanin in Sol. verbascifolium. Ibid. Vol. I. p. 517-521.

Peschier, Auffindung einer angeblichen Solansäure, die sich als identisch mit Aepfelsăure herausstellte. Ibid. Vol.III. p. 289. 1827 u. Trommsdorff's Journ. d. Pharm. XIV. Bd. S. 269.

* Baup, Nachweis des Vorkommens von Solanin in Kartoffeln. Annales de chimie et de physique. Vol. XXXI. p. 109. 1826.

Pelletier, Auffindung von Solanin in Sol. mammosum. Journal de pharmacie. Vol. XIV. p. 256. 1828.

Spatzier, Incorrecte Angaben über Darstellung von Solanin aus Kartoffeln. Schweigger-Seidel's Journal für Chemie und Physik. LXI. Bd. S. 311-313. 1831.

Doebereiner, Controle und Widerlegung von Spatzier's Angaben. Ebenda. IXXII. Bd. S. 99. 1831.

Herberger, Controle und Widerlegung von Spatzier's Angaben. Buchner's Repertorium. XXXIX. Bd. S. 480. 1831.

Fôdéré und Hecht, Auffindung von Solanin in Sol. lycopersicum. Ann. chem. pharm. III. Bd. S. 130. 1831.

Henry und Legrip, Elementaranalyse von Solanin aus Sol. dulcamara. Journal de pharmacie. Vol. XVIII. p. 661-665. Ann. chem. pharm. VIII. Bd. S. 198. 1833. Schweigger-Seidel's Journ. f. Chemie u. Physik. LXVIII. Bd. S. 77. 
Beiträge zur Kenntniss der Wirkungen des Solanins und Solanidins. 129

Buchner, A., Controle und Kritik ron Spatzier's Angaben. Journal f. prakt. Chemie. II. Bd. S. 272-274. 1834. Ann. chem. pharm. XII. Bd. S. 250. Buchner's Repertorium. XLVIII. Bd. S. 337-361.

Otto, F. J., Darstellung von angeblichem Solanin, in Wahrheit von - mindestens grösstentheils - Solanidin aus Kartoffeltrieben; die beschriebenen Reactionen stimmen nicht auf Solanin, sondern Solanidin. Journ. f. prakt. Chemie. I. Bd. S. 58-74. 1834. Ann, chem. pharm. VII. Bd. S. 150-151; XXVI. Bd. S. 232.

Blanchet, Elementaranalyse von Otto's Solanin. Ann. chem. pharm. VII. Bd. S. 152. 1834. Ann. de chimie et de physique. Vol. LIII. p. 414.

Heumann, Modification der Otto'schen Darstellungsmethode. Buchner's Repertorium. LXXIV. Bd. S. 125. 1839.

Reuling, Modification der Otto'schen Darstellungsmethode. Ann. chem. pharm. XXX. Bd.S. 225-228. 1839.

v. Liebig, J., Solanin soll nur in eingekellerten und nicht in auf dem Felde gekeimten Kartoffeln vorkommen. Ferschiedenheit des Solanins in verschiedenen Solaneen vermuthet. Die organ. Chemie in ihrer Anwendung anf Agricultur und Physiologie. Braunschweig 1840. S. 92. Geiger's Handbuch der Pharmacie. V. Aufl. 1843. II. Bd. S. 1213.

Winckler, Vergleichende Darstellung aus Solanum tuberosum, nigrum und dulcam. Buchner's Repertorium. LXXVI. Bd. S. 384. Berzelius' Jahresber. XXIII. Bd. S. 363. Jahrb. f. prakt. Pharmacie. IV. Bd. S. 143.1843.

Wackenroder und Weber, Darstellung von unreinem Solanin aus Kartoffeltrieben. Archiv d. Pharm. XXXIII. Bd. S. 59. Berzelius' Jahresber. XXIV. Bd. S. 404. 1844 .

Ba u mann, H., Einige Reactionen und Löslichkeitsverhältnisse von Solanin. Pharmaceut. Centralbl. 1844. S. 649-651. Archiv d. Pharmacie. XXXIV. Bd. S. 23 u. 158; XXXV. Bd. S. 137; XXXVIII. Bd. S. 292 u. 295. Berzelius' Jahresber. XXIY. Bd. S. 408.

Has s old, Einige Reactionen von Solanin. Buchner's Repertorium. XCIV. Bd. S. 70. 1848.

Ka rmrodt, Darstellung von mellithsaurem Solanin. Ann. chem. pharm. LXXXI. Bd. S. 171.1856.

M oites sier, Analysen von Solanín aus Sol. dulcamara. Comptes rendus. Vol. XLIII. p. 978. 1856. Ann. chem. pharm. CI. Bd. S. 368. Journ. f. prakt. Chemie. LXXI. Bd. S. 308. Chem. Centrbl. 1857. S. 124. Liebig u. Kopp's Jabresber. 1856. S. 547.

Delffs, Elementarzusammensetzung von Solanin. Chem. Centralbl. 1859. S. 800 . Jahrb. f. prakt. Pharmacie. XI. Bd. S. 356.

Gmelin, O., Spaltung in Zucker und Solanidin. Ann. chem. pharm. CX. Bd. S. 167 bis 176. Chem. Centrbl. 1859. S. 567-570. Chemical Gazette 1859. p. 385. Repertoire de chimie pure. Vol. I. p. 437. Liebig u. Kopp's Jahresberichte. 1859. S. 402.

Zwenger und Kind, Spaltung in Zucker und Solanidin entdeckt. ElementaranaIysen von Solanin, Solanidin und mehreren Salzen derselben, Eigenschaften und Reactionen beider. Ann. chem. pharm. CIX. Bd. S. 244; CXVIII. Bd. S. 129; CXXIII. Bd. S. 341 . Chem. Centralbl: 1859. S. 431 ; 1861. S. 601; 1862 . S. 780. Liebig u. Kopp's Jahresber. 1859. S. 402; 1861. S. 535; 1862. S. 382. Kritische Zeitschr. f. Chemie. V. Bd. S 527 . Ann. de chimie et de physique. Vol. LXIII. p. 377. Repertoire de chimie pure. Vol. V. p. 154.

A rchiv f. experiment. Pathel. n. Pharmakol. XXYI. Bd. 
*Wittstein, Quantitative Bestimmung des Solanins in Kartoffeln von fraglicher Genauigkeit. Pharmaceut. Vierteljahrschr. I. Bd. S. 364. 1861.

*Wolff, J., Einige Reactionen. Ebenda. II. Bd. S. 503. 1861.

Kromay er, A., Darstellung von möglichst solanidin-freiem Solanin aus Kartoffeltrieben. Archiv d. Pharmacie. CXVI. Bd. S. 114. Chem. Centralbl. 1863. S. 1054. Liebig u. Kopp's Jahresber. 1863. S. 450.

Hager und Neubauer, Reactionen. Pharmaceut. Centralhalle. 1863. Zeitsch. f. analyt. Chemie. 1872. S. 203.

Enz, J. B., Solanin in den Kernen von Sol. lycopersicum. Archiv d. Pharmacie. CXV. Bd. S. 92. 1863. Wittstein's Vierteljahrschr. f. prakt. Pharmac. XI. H. 3.

Helvig, Mikrochemischer Nachweis. Zeitschr. f. analyt. Chemie. 1864. H. 55.

Haaf, C., Quantitative Berechnung des Solaningehalts in verschiedenen Theilen der Kartoffel zu verschiedenen Jahreszeiten. Buchner's neues Repertoriam. XIII. Bd. S. 559. Chem. Centralbl. 1865. S. 749. Jahrb. f. Agriculturchemie. 1865. S. 121. Erhard, Mikrochemische Reactionen. Neues Jahrbuch f. Pharmacie. XXVI. Bd. S. 129.

Kletzinsky, Elementaranalyse des Solanins und angebliche Spaltung in Nikotin und Buttersäure. (Unwahrscheinlich, aber noch exact zu widerlegen.) Mittheilungen aus dem Wiener Laboratorium 1865. Krit. Zeitschr. f. Chemie. 1866. S. 127. Bull. de la société chimique. Vol. VII. p. 457.1867.

Hoffman, Solanin in Sol. bacciferum. Edinb. medical Journal. Nov. 1867.

*Wormley, Mikrochemische Reactionen. Microchem. of poysons. N.-Y. 1869.

Bach, O., Farbenreaction mit concentrirter Schwefelsäure. Journ. f. prakt. Chemie. (2.) VII. Bd. S. 248. 1873.

*S elmi, Mikrochemische Reactionen. (Nuovi reattivi per ricognoscere e discernere gli alcaloide venefici.) Mem. dell' academia delle scienze di Bologna. Ser. 3 a. T.VI. p. 193.1875 .

Jagi, Angeblich Solanin in Scopolia japonica. Archiv d. Pharmacie. CCXIII. Bd. S. 336. 1876.

Missaghi, Angeblich Solanin in Solanum sodomeum. Berichte der Berliner chem. Gesellschaft. 1876. S.83.

*Brandt, Färbung mit Schwefelsäure und Selensäure. Ueber einige neue Alkaloidreactionen. 1876.

Hilger und Martin, Elemẹtaranalyse von Solanin und Solanidin. Ann. chem. pharm. CXCV. Bd. S. 317. 1879.

*v. Renteln, Beiträge zur forensischen Chemie des Solanins. Dorpater Dissertation 1881.

*Ebermayer, Vorkommen von Solanin in grünen und etiolirten Kartoffelkeimen. Physiolog. Chemie der Pflanzen. I. S. 479. 1882.

Dragendorff, Exacte Angaben über Reactionen von Solanin und Solanidin, über Löslichkeitsverhältnisse und Methode des Nachweises. Gerichtlich-chem. Ermittelung der Gifte. S. 315; Journal de pharmacie. V. série. 6. 1882. Pharmaceut. Zeitschr. f. Russl. XXI. Bd. S. 612 (15. Aug. 1882). Analyse chimique des végeteaux. 1885 .

Ga enge, Spectrum der Lösung von Solanin und Solanidin in conc. Schwefelsäure. Lehrb. d. angew. Optik. 1889.

*Mandelin, Mikrochemische Reactionen. Pharmac. Zeitschr. f. Russl. 1883. S. 351.

Schaarschmidt, J., Mikrochemische Reactionen. Zeitschr. f. wissenschaftliche Mikroskopie I. 1884. Chem. Centralbl. 1884. S. 330. 
Beiträge zur Kenntniss der Wirkungen des Solanins und Solaniđins. 131

Wothschall, E., Reaction mit vanadinsaurem Ammonium und Schwefelsäure. Mikrochemischer Nachweis im Pflanzengewebe. Zeitschr. f. wissenschaftliche Mikroskopie V. Heft. 1 u. 2. 1888.

\section{B. Pharmakologische Literatur.}

*Dunal, Erwähnung von Vergiftungsfällen mit Solaneen. Histoire naturelle médicale et économiste des Solanum. Montpellier 1815.

Malik, Aufstellung der irrigen Hypothese, dass die Rinderpest anf einer Solaninvergiftung durch Schlempefütterung beruhe. Henke's Zeitschr. f. Staatsarzneikunde. XV. Bd. Ergänzungsheft. S. 185-218. 1831. Frank's Magazin f. physiol. u. klin. Arzneimittellehre u. Toxikologie. XIII Bd. S. 321-325.

Hens chel, Solanin in Solanum lycopersicum. Ann. chem. pharm. VIII. Bd. S. 332. 1833.

Bennet, Solanin in Solanum lycopersicum. Ibid. XX. Bd. S. 262.1836.

*Bourgeois, Vergiftung durch unreife Kartoffeln. Journal général de méd. Vol. 344. p. 69 .

*D u feuilly und Mo rri son, Darstellung von Solanin aus Solanum nigrum. Journ. de chimie médicale. Vol. VI. 1839.

Hirtz, Vergiftungsfall durch Solanum nigrum. Gazette médicale de Strasbourg. 1842.

*Hei m, Ernst Ludwig, Vergiftung durch unreife Kartoffeln. Hinterlassene Schriften. Muncke, Fall von Vergiftung durch unreife Kartoffeln. Medic. Annalen. 1845. XI. Bd. 2. Heft.

M'Cormack, Epidemie nach anhaltendem Genuss kranker Kartoffeln. Lancet. Juli 1846. Dublin. Hosp. Gaz. Januar 1846.

O'Brien, Fall von Vergiftung durch unreife Kartoffeln. Lond. medic. Gaz. 1846. p. 333.

Orfila, Vergiftung von Kindern und Thieren mit Beeren von Solanum nigrum. Lehrbuch der Toxikologie, deutsch von Krupp. II. Bd. 1853.

Fraas, Fütterungsversuche an Schweinen, die eine Immunität derselben gegen Solanin aus gekeimten Kartoffeln zu beweisen schienen. Virchow's Arch. 6. Bd. S. 225-237. 1854. Bericht über die Leistungen in der Pharmakodynamik und Toxikologie von Falk. 1855. S. 103-104.

B o urneville, Vergiftungsfall mit Beeren von Solanum dulcamara. Gazette des hôpiteaux. 1854, p. 35.

Ede, Fall von Vergiftung durch. junge Kartoffeln. Lancet 1856.

Schroff, Versuche mit Dulcamara-Solanin an Menschen; Symptome: hauptsächlich Gastroenteritis. Solanin wird als Antidyscraticum empfohlen. Lehrbuch der Pharmakologie. 1856. S. 552. Lehrb. der Pharmakognosie. S. 286-287.

v. Praag, Vergiftungsversuche an Hunden, Kaninchen und Tauben. Journal $f$. Pharmakodynamik I, 2. S. 275. 1857.

Clarus, Versuche mit Solanin (wahrscheinlich aus Dulcamara), mit Extractum und Decoctum Dulcamarae. Ungefähre Constatirung, aber falsche Auslegung einiger Wirkungen. Applicationsart: ausschliesslich Einspritzung in den Magen. Ebenda. S. 245. 1857.

*Magne, Tödtliche Vergiftung durch Beeren von Sol. dulcamara. Gazette des hôpiteaux. 1859. p. 112.

Hoppe, Die Nervenwirkungen der Arzneimittel. Versuche an Fröschen und Organtheilen von solchen. 
132 VI. PeRLes, Beiträge zur Kenntniss d. Wirkungen des Solanins u. Solanidins.

Norris, Tödtliche Vergiftung durch Beeren von Sol, tuberosum. British medic. Journ. 1859 .

Montané, Vergiftung durch Beeren von Sol. pseudocapsicum. Archiv der Pharmacie. CXV. Bd. S. 264. Pharmaceut. Vierteljahrschr. XI. Bd. H. 4. Journ. de chimie médicale. Vol. XXXVIII. p. 24. 1862.

Leydorf, Beschreibung der nach Einbringung von Solanin zweifelhafter Herkunft per os an Tauben und einem Kaninchen beobachteten Erscheinungen. Solanin wird als Narcoticum acre bezeichnet. Studien über den Einfluss des Solanins auf Thiere and Menschen. Inaug.-Dissertation. Marburg 1863.

Haf, Untersuchung des Solaningehaltes in verschiedenen Theilen der Kartoffeln in verschiedenen Keimstadien. Schweizerische Wochenschr. f. Pharmacie. 1863. Nr. 30 u. 31.

Bourdin, Fall von Vergiftung mit Beeren von Sol. dulcamara. Gaz. des hôpitaux. 1864. Lancet. Juni 1856.

Maury, Vergiftung mit Sol. nigrum. Gaz. des hôpitaux. 1864. p. 35.

Fronmüller, Versuche an Străflingen, die bis zu $1 \mathrm{~g}$ Solanin einnahmen und darauf nur auf Stunden erkrankten. Klin. Studien 1869. Deutsche Klinik 1865. Nr. 40.

*Manners, Vergiftung mit Sol. bacciferum. Edinb. medic. Journ. 1867. p. 398.

Tardieu, Vergiftungsfälle mit Solaneen. L'empoisonnement. 1867.

* Barthez, Fall von Vergiftung durch Beeren von Sol. pseudocapsicum. Journ. de chim. médic. Jan. 1869.

Ba lmañya, Erscheinungen nach subcutaner Injection von Solanin und Solanidin an Fröschen, Salamandern, Kaninchen und Tauben. Versuche über die Wirkung des Solanins und Solanidins. Inaug.-Dissert. Göttingen 1874.

Husemann, Ausführliches Referat über das Vorige. Dieses Archiv. IV. Bd. 1875. S. 369.

*Niemtschenk off, Tödtliche Vergiftung von Schweinen durch gekeimte Kartoffelknollen. Ueber Kartoffeln und ihre Nahrbaftigkeit. Petersburg 1886. p. 39. (Russisch.)

Grasset und Sarda, Solanin gegen das Zittern bei multipler Sklerose, tabischen Schmerzen u. s. w. empfohlen. Progrès méd. 1888. No. 27. Bullet. génér. thérap. 30. Mai 1888.

Geneuil, Solanin als Ersatzmittel für Morphin empfohlen. Bullet. génér. thérap. 1886. Vol. CXI. No. 6.

Gaignard, Solanin in Tagesdosen von $0,3-0,4 \mathrm{~g}$ obne Effect. Ibid. 1887. Vol. CXIII. No. 1.

\section{Erklärung der Abbildungen.}

(Tafel III u. IV.)

1. Kaninchen-Ileum mit Ol. Terebinth. diaphan gemacht. Intravenöse Solaninvergiftung. Vergr. Zeiss $\mathrm{Obj}$. 3, Ocul. III. Tubusl. 180. Hämorrhagischinfiltrirte Peyer'sche Plaques, Hyperämie und Hämoglobin-Imbibition.

2. Hunde-Ileum. Alkohol-Boraxcarmin-Präparat. Intestinale Solaninvergiftung. Vergr. Zeiss Obj. 3, Ocul.I. Tubusl.180. Hämorrhagisch-desquamative und folliculäre Enteritis.

3. u. 4. Katzen-Niere. Alkohol-Boraxcarmin-Präparat. Intravenöse Solanidinvergiftung. Vergr. ebenso. Hämoglobininfarct. Hämorrhagische Nephritis. 

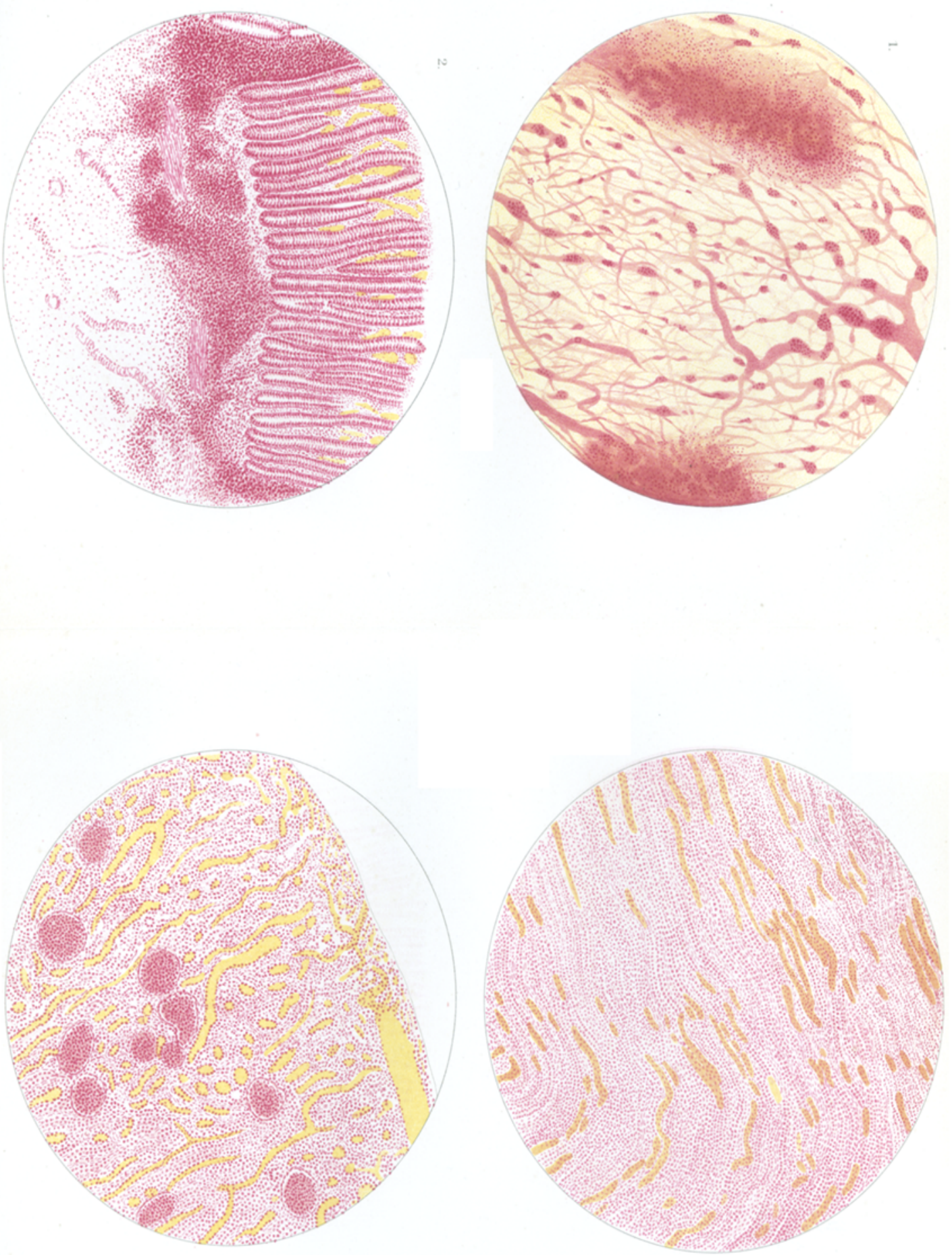